Portland State University

PDXScholar

5-28-1996

\title{
The Demographics, Motivations, and Role Conceptions of Student Nurses
}

Steven C. Von Flue

Portland State University

Follow this and additional works at: https://pdxscholar.library.pdx.edu/open_access_etds

Part of the Sociology Commons

Let us know how access to this document benefits you.

\section{Recommended Citation}

Von Flue, Steven C., "The Demographics, Motivations, and Role Conceptions of Student Nurses" (1996). Dissertations and Theses. Paper 5142.

https://doi.org/10.15760/etd.7018

This Thesis is brought to you for free and open access. It has been accepted for inclusion in Dissertations and Theses by an authorized administrator of PDXScholar. Please contact us if we can make this document more accessible: pdxscholar@pdx.edu. 
The abstract and thesis of Steven $C$. Von Flue for the Master of Science in Sociology were presented May 28, 1996, and accepted by the thesis committee and the department.

COMMITTEE APPROVALS:
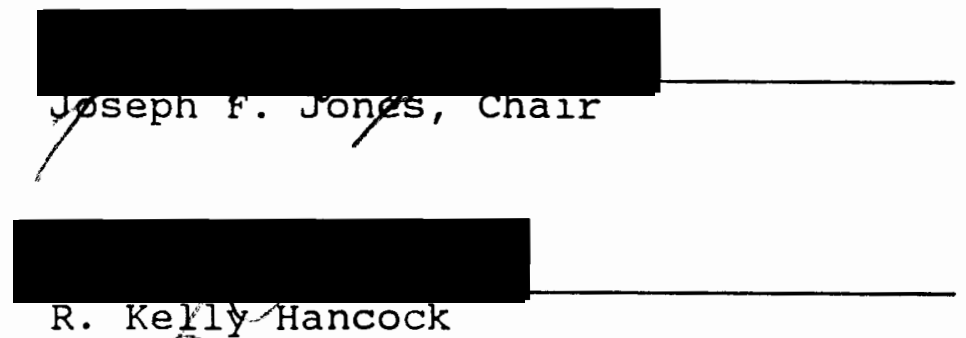

R. KeYly Hancock

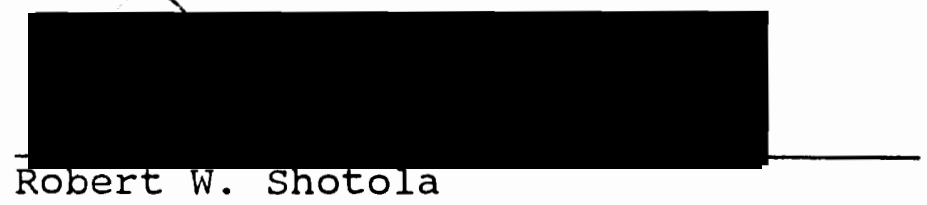

DEPARTMENT APPROVAL:

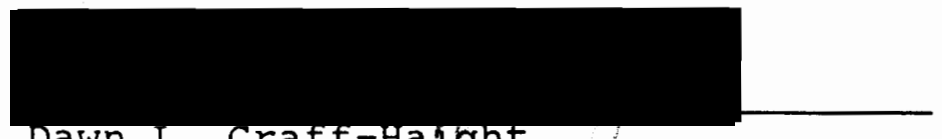

Dawn L. Graff-Haight

Representative of the office of Graduate studies

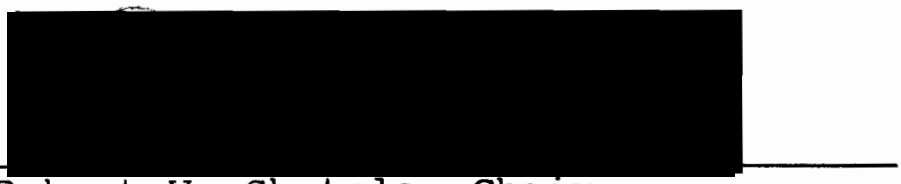

Robert W. Shotola, Chair

Department of Sociology

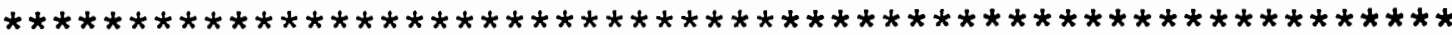

ACCEPTED FOR PORTLAND STATE UNIVERSITY BY THE LIBRARY

by

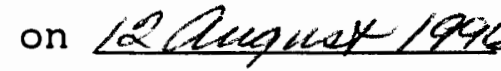




\section{ABSTRACT}

AN ABSTRACT OF THE THESIS OF steven $c$. Von Flue for the Master of Science in Sociology presented May 28, 1996.

Title: The Demographics, Motivations, and Role Conceptions of student Nurses.

This thesis investigates the following factors concerning student nurses: (1) demographic background and life experiences; (2) motivations to enter and commitment to nursing school; (3) students' conceptions of the role of a nurse; (4) comparison of students' expectations with their ideals and with the realities of nursing.

A questionnaire was administered to first year nursing students at three institutions; a four-year baccalaureate degree program and two community college associate degree programs. The two types of institutions were chosen to allow comparison between students on two different career tracks.

The findings indicate that contemporary student nurses are older than typical college students, have had a significant number of prior occupational experiences, and in contrast to the $1960^{\prime}$ s and earlier, are not exclusively female. They were most strongly motivated to be nurses by the desire to help others and conceive of the role of a 
nurse as challenging, rewarding, and relatively

professional. In general, these students had a good understanding of the role of the average nurse, but they would construct the ideal nursing environment somewhat differently than the actual nursing environment.

These findings relate to career exploration and motivational processes associated with occupational training. It can be inferred from survey data that initiates to training programs often are quite aware of what the discipline demands. In many cases they have sought out others who are working in the field. These data also reflect the increasing occupational mobility of American society whereby individuals change careers once or more during their lifetimes. 
THE DEMOGRAPHICS, MOTIVATIONS, AND ROLE CONCEPTIONS OF STUDENT NURSES

\author{
by \\ STEVEN C. VON FLUE
}
A thesis submitted in partial fulfillment of the requirements for the degree of

\author{
MASTER OF SCIENCE \\ in \\ SOCIOLOGY
}

\author{
Portland State University \\ 1996
}




\section{ACKNOWLEDGEMENTS}

I want to thank my friends and family who gave me the moral support to complete this thesis.

I wish to thank my thesis committee members for their help and patience.

I especially want to thank Dr. Joseph F. Jones for his assistance, patience, and prompting, without which I may never have finished this thesis. He went above and beyond what is required of a thesis chair.

Finally, I want to thank Sherri L. Stallings for her support and encouragement. 
TABLE OF CONTENTS

PAGE

IIST OF TABLES $\ldots \ldots \ldots \ldots \ldots \ldots \ldots \ldots \ldots \ldots \ldots \ldots \ldots \ldots$

IIST OF FIGURES ........................ vii CHAPTER

I INTRODUCTION $\ldots \ldots \ldots \ldots \ldots \ldots \ldots \ldots \ldots \ldots \ldots \ldots \ldots \ldots \ldots \ldots$

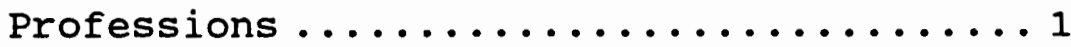

The Professional status of Nursing ...... 3

Motivations in a Dynamic Discipline ..... 5

Problem statement ................. 8

II THEORETICAL FRAMEWORK AND BACKGROUND ........ 11

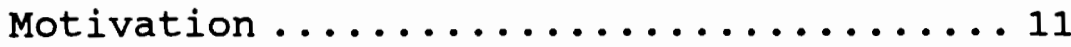

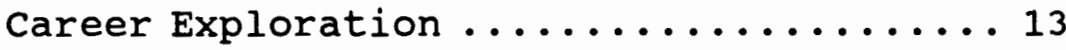

Commitment ....................... 14

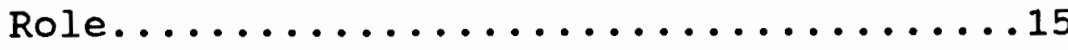

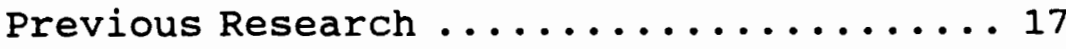

Demographics and Iife Experiences

Student Motivations

Conceptions of the Nurse's Role

Comparison of Expectations, Ideals, and Reality

III METHODOLOGY ...................... 34

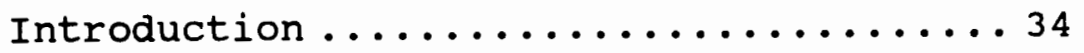

Limitations and Assumptions ......... 36

Inter-coder Reliability ........... 37 


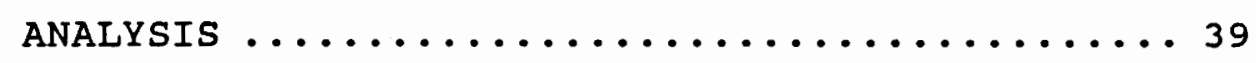

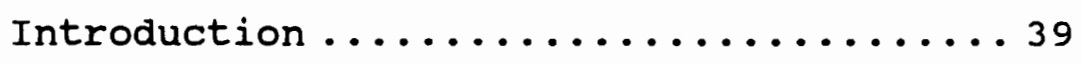

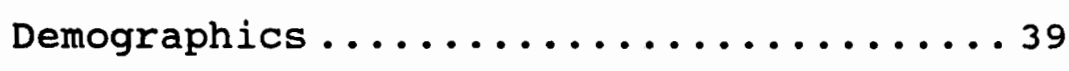

Motivations to study Nursing ......... 45

Conceptions of Role ............... 57

Expectations, Ideals, and Reality ..... 66

Expectations and Reality

Expectations and Ideals

V SUMMARY AND CONCLUSION ................ 80

Summary of Demographics ............ 80

Summary of Motivations ............81

Summary of Conceptions of Role .......8 83

Summary of Expectations, Ideals,

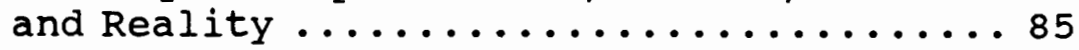

Summary of Expectations and Reality

Summary of Expectations and Ideals

Suggestions for Future Research .......887

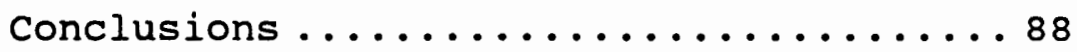

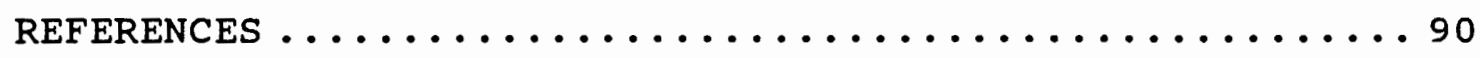
APPENDICES

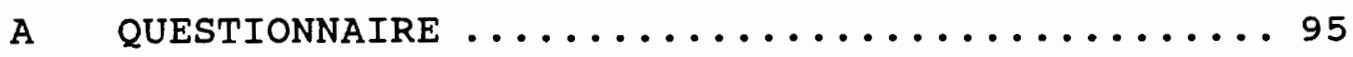

B RESEARCH APPROVAL REQUEST AND APPROVAL ...... 103 


\section{LIST OF TABLES}

TABLE

PAGE

I student Characteristics ...............43

II Students' Future Work Intentions, contrasted by Type of College .............445

III Importance of Factors Influencing the Decision to study Nursing .........447

IV Importance of Factors Influencing the Decision to study Nursing, Contrasted by Type of College ........499

$\mathrm{V}$ Importance of Categories of People Influencing the Decision to study Nursing ................. 51

VI Importance of Categories of People

Influencing the Decision to study Nursing, Contrasted by Type of college ............... 52

VII Individuals or Events Having Influence on the Decision to Study Nursing ...... 54

VIII Importance of Social and Socio-economic

Factors in the Decision to study Nursing ....................... 55

IX Importance of social and socio-economic

Factors in the Decision to study 
Nursing, Contrasted by Type of College ..................... 56

$\mathrm{X}$ Importance of Factors to students in their

Future Roles as Nurses ............ 59

XI Importance of Factors to students in their

Future Roles as Nurses, Contrasted by

Type of College ...............61

XII Importance of Characteristics to

Being a Good Nurse ..............6 62

XIII Importance of Characteristics to Being

a Good Nurse, Contrasted by

Type of College ................664

XIV Future Importance of Various Tasks to the

Students as Nurses and students'

Beliefs Concerning how often the

Average Nurse Engages in these Tasks ...72

XV Future Importance of Various Tasks to the

Students as Nurses and students'

Beliefs Concerning how often

the Average Nurse Engages in these

Tasks, Contrasted by Type of college ...77 


\section{LIST OF FIGURES}

FIGURE

PAGE

I Percentage of Nursing Students Enrolled in Diploma, Baccalaureate, and Associate Degree Programs in 1960, 1976, and $1991 \ldots \ldots \ldots \ldots$ 
CHAPTER I

\section{INTRODUCTION}

How do adults make decisions that lead to careers in professions? What factors motivate them and shape their aspirations? How do those training for an occupation conceive of their future role and how does this conception compare with that of established workers in the field? Questions such as these can be explored through the investigation of student nurses and schools of nursing.

Considerable research has been conducted concerning the motivations of and the training of those entering established professions. The professional status of nursing, however, remains unclear. Students' motivations for entering nursing school and their conceptions of nursing are likely related to whether or not they see nursing as a profession. Before investigating students' conceptions of the professional status of nursing it seems useful to define "profession" and to assess the status of nursing as a profession.

\section{PROFESSIONS}

Prior to the 1670's "profession" was exclusively a religious term, referring to a declaration or profession of 
faith. By the Eighteenth century it had acquired secular significance meaning "having claim to due qualifications" (Brown 1992, p. 18). Eventually, the meaning of profession was expanded to include many other occupations such as business, science, and engineering.

Who is a professional is subject to a variety of interpretations. First, professionals are workers "whose qualities of detachment, autonomy, and group allegiance are more extensive than those found among other workers" (Brown 1992, pp. 18-19). This definition is not complete, however, because it does not separate professional work from skilled craft-work.

Another interpretation holds that professionals monopolize expertise. Randall collins builds upon this, maintaining that professionals cannot be defined only on the basis of monopolized knowledge because many trade workers possess exclusive knowledge. He concludes that the social organization of the knowledge is also important. In most trades, skilled workers do not receive extensive formal educations. Professions have an academic basis not present in other occupations and trades (Collins 1990, pp. 18-19) .

Sociologist Eliot Freidson maintains that professions can be distinguished from other occupations because professionals in training are required to engage in protracted higher learning (Brown 1992, p. 19). In his 
study of the medical profession, Freidson arrives at two different views of what constitutes a profession. First, a profession is:

An aggregate of people finding identity in sharing values and skills absorbed during a course of intensive training through which they all have passed... one determines whether or not an individual "is" a professional by determining whether or not he has internalized certain given professional values (Freidson 1970, p. 81).

And second:

A group of workers joined together on the most general level by virtue of sharing a particular position in society and by common participation in a given division of labor. One defines a professional by his status, regardless of the norms to which he subscribes, and explains his behavior by referring to the work structure in which he participates (Freidson 1970, p. 82).

A comprehensive definition of "profession" can be constructed from these interpretations. First, professionals are defined by the qualities of detachment, autonomy, and group allegiance. Professionals possess an exclusive knowledge base which can be acquired only through extensive formal education. A professional has internalized the values of the profession, is defined by his or her status, and explains behavior by referring to the work structure of the profession.

THE PROFESSIONAL STATUS OF NURSING

The status of nursing as a profession appears undetermined. One perspective maintains that nursing is not a full-fledged profession, but rather a semi-profession 
because it does not have exclusive control of a body of knowledge. Fred Katz explains that:

Despite the effort of many nursing leaders for the professionalization of nursing, the physician is still the chief determiner of the kind of knowledge that is used in the medical setting. The nurse... has no clearly formulated body of professional knowledge that is recognized and accepted by others (Katz 1969, p. 62).

Consistent with this perspective, Amitai Etzioni declares that nursing is a semi-profession because:

Nurses apply knowledge, but their training is much shorter than doctors, and the question of what therapy to administer is concentrated in the hands of the doctors.... (Etzioni 1969, p. XIV).

Etzioni also maintains that nurses have less autonomy than members of full-fledged professions. They are more closely observed and directed by supervisors (Etzioni 1969, p. XIV).

These accounts of the professional status of nursing are several decades old and may not be accurate. Current literature invariably refers to nursing as a profession (Kapsar 1982; Mendez and Louis 1991; Greenwood 1993; Kiger 1993; Parisi, Johnson, and Keil 1993; and Hurley 1994). Aant Elzinga, in her study of Swedish nurses, maintains that nursing has professionalized through the establishment of an independent research capability (Elzinga 1990, p. 156). Nursing may not be fully accepted as a profession by all, including those in training, but nursing educators clearly view nursing as a profession.

Nursing literature is filled with numerous references 
to professional nurses and the goal of most contemporary nursing programs is to produce college-educated professionals who are innovative thinkers trained for positions such as hospital administration, preventative medicine, and general supervision of allied health care workers (Fox 1989, pp. 64-67; Cockerham 1992, p. 202). Depending upon what attracts applicants to nursing programs, they may or may not see the role of a nurse in this way. It remains to be determined whether or not today's student nurses conceive of nursing as a profession with professional duties and responsibilities.

\section{MOTIVATIONS IN A DYNAMIC DISCIPLINE}

Aspiring nurses have traditionally viewed nursing as a caring occupation. Many 1960's students appeared to be attracted to nursing by the image of a nurse as a "caregiver at the bedside" who wore a stiffly starched uniform and who spent most of "her" time interacting with patients on a large hospital ward (Davis 1966, pp. 163164). Perhaps entering students still view nursing this way, but it is clearly not the image promoted by schools of nursing (Corwin 1960, pp. 607-608; Fox 1989, p. 64). Nursing schools may be fostering a new image of nursing because of changes in nursing, changes in the structure of nursing schools themselves, and changes in the demographics of student nurses. Nurses have more 
specialized roles in an increasing number of areas. Nursing schools have tightened entrance requirements and increased tuition, and competition for entrance has escalated. Additionally, student nurses are older and more likely to be male than in the 1960's.

Many nurses are no longer working in hospitals, but rather in environments which provide opportunities to be more creative and professional. This is the result of growing demand for "professional" nurses in areas such as home health care, risk management, health insurance, occupational health and safety, and other government and private industry positions (Gothler and Rosenfeld 1986, p. 559). Student nurses' motivations and conceptions of nursing likely reflect these changes.

coinciding with the aforementioned changes in the role of nurses, schools of nursing have raised their entrance requirements and competition for acceptance has increased (Nursing Data Source 1992, p. 15). These changes could signal increased professionalization of nursing in that limiting the number of new members is a practice of most, if not all, professions.

Additionally, tuition at nursing schools has risen significantly in recent years. The increases are greatest in public schools offering associate degree programs, which experienced a forty-one percent rise in tuition from 1991 to 1992 (Nursing DataSource 1993, p. 16). Tuition 
increases further serve to limit those wishing to enter nursing programs.

Change has also occurred in the demographics of student nurses as larger numbers of males and older individuals enroll in nursing programs (Hess 1983, p. 28; Nursing Datasource 1992, pp. 19,21; Nursing Datasource 1993, p. 18; Nursing Data Review 1993, pp. 21,23). The changes indicated above will likely be reflected in the motivations and conceptions of student nurses.

The decisions made by, as well as the motivations and conceptions of, student nurses do not occur in a vacuum. Individuals' lives take place within a social and historical context. Sociologist C. Wright Mills (1959, pp. $3,5-6)$ refers to this in his discussion of the sociological imagination:

The sociological imagination enables us to grasp history and biography and the relations between the two within society. ---

The facts of contemporary history are also facts about the success and the failure of individual men and women. When a society is industrialized, a peasant becomes a worker; a feudal lord is liquidated or becomes a businessman. --- Neither the life of an individual nor the history of a society can be understood without understanding both. ---

The sociological imagination enables its possessor to understand the larger historical scene in terms of its meaning for the inner life and the external career of a variety of individuals.

It is likely that the social changes which occurred in the United States beginning in the 1960's are in part responsible for the changes in nursing students and nursing education. For example, the Women's Movement is probably a 
factor behind the increased professional outlook of both nursing schools and nursing students in the 1990's. Additionally, the disappearance of clearly defined male and female roles in the work-place no doubt is related to the larger numbers of men in nursing schools today. The perspectives and demographic makeup of individual nursing students are intertwined with the social and historical context in which they reside.

\section{PROBLEM STATEMENT}

Increases in professionalization, competition, and tuition, as well as shifting demographics, may signal a change in the "bedside care" image and the motivations of aspiring nurses. The aim of this thesis is to investigate these possible changes. Four general question areas frame this inquiry:

1). What is the demographic makeup and what are the life experiences of contemporary initiates to nursing school?

2). What motivates an individual to seek admission to a nursing program? Are student nurses fully committed to life-long careers in medical care?

3). How do entering students conceive of the role of a nurse?

4). Are initiates' expectations consistent with the realities of nursing practice? Are initiates' expectations consistent with their nursing ideals?

These questions take on added importance in light of the nationwide nursing shortage in certain health and 
medical care environments as well as nursing specialties. It is crucial for nursing programs to attract students who are qualified for and who will adapt well to current and future nursing realities. A survey by the American Nurses Association in 1989 found that critical shortages existed in health maintenance organizations, home health agencies, nursing homes, and critical care units in hospitals. One explanation given for this shortage is declining interest in nursing careers among female freshmen college students (Grossman and Northrop 1993, p. 157). This underscores the importance of understanding the motivations of aspiring nurses so that they can be properly informed about and exposed to these issues.

The occupational outlook for nurses has been complicated, however, by the rapid change in health care delivery. In general, the 1990's have not seen a comprehensive shortage of nurses; in fact, a surplus exists in many areas. In order to cut costs aides and other less skilled workers have been brought in to replace registered nurses. Hospitals, like other businesses, have been undergoing downsizing and restructuring. Staff positions, including nursing jobs, have been cut. Nationwide, 44,700 hospital jobs have been eliminated in the last two years. Hospital stays are getting shorter with an emphasis on same-day surgeries and outpatient care (Sullivan 1995, p. B15) . 
Although no pressing overall shortage exists in the 1990's, there is still a great need for nurses in specific areas. These areas include home care and private practice in which nurses diagnose and prescribe. These positions likely represent the future of nursing, but they generally require education beyond a registered nurse degree (Sullivan 1995, p. B15). More managerial and training skills, as well as independence, are likely to be demanded of future registered nurses. This thesis strives to clarify the question of whether student nurses are aware of and understand the changing structure of nursing as this may impact their motivations and conceptions. 
CHAPTER II

THEORETICAL FRAMEWORK AND BACKGROUND

MOTIVATION

The study of motivation is an investigation into the "why" of behavior (Deci and Ryan 1985, p. 3). Herbert Petri defines motivation as "... the concept we use when we describe the forces acting on or within an organism to initiate and direct behavior" (Petri 1986, p. 3). Motivation is generally not measured directly, rather some stimulus condition is observed or manipulated and a response behavior is measured. Motivation can be inferred from any change in behavior that occurs (Petri 1986, pp. 4,11-12). There are many facets of motivational theory and it is not possible to summarize them all here. Some general ideas and theories concerning motivation, however, can be outlined.

Approaches to motivation range from the nomothetic (based on general laws applicable to a large number of situations) to the idiographic (founded on understanding behavior by looking at how people differ from each other and at what makes them unique). Motivations may be controlled innately by instinct or alternatively, motive states may be acquired or learned (Petri 1986, p. 12). 
Some theorists believe internal events such as wishes, urges, expectancies, and thoughts are important in causing behavior. These theorists do not deny the importance of the situation, but maintain that the aforementioned internal events occur within a causal chain or mediate between situation and action (Mook 1987, p. 10). Humans as well as other animals have needs which act as internal or intrinsic sources of motivation that direct behavior toward the environment in a way which satisfies the needs. C.I. Hull's drive theory states that all behaviors are based in four primary drives: hunger, thirst, sex, and the avoidance of pain. Behaviors are either motivated directly by primary drive stimuli or by derivative sources through secondary reinforcement. Through reinforcement various stimuli become associated with responses and behaviors. Primary drives remain the root source of motivation, but only through association with stimuli (Deci and Ryan 1985, p. 12) .

In contrast to intrinsic theories of motivation which hold that internal events are responsible for behavior, behavioral theory holds that behavior is caused by environmental factors. These causes are outside the organism, in the environment. Environmental events may cause actions directly, as in a reflex response to pain, or actions may be strengthened and reinforced gradually by environmental events, as when a rat is trained to push a 
lever to obtain food. A committed behaviorist views thoughts, feelings, and other internal events as actions which are caused by the same environmental events that cause external behavior (Mook 1987, pp. 9-10).

Motivation, like behavior, can arise from changes in the external environment (Petri 1986, pp. 12-13). In complicated human society, social forces influence motivations to learn, to work, and to participate in activities. Extrinsic theories of motivation may allow for the importance of basic drives, but they also maintain that there is much more to human behavior. Abraham Maslow believed that basic drives are important, but once elementary needs are met, other and higher social needs emerge (Maslow 1970, p. 38). This coincides with the view that human behaviors are significantly influenced by situational factors (the social and physical environment) and by the presence of other people (Petri 1986, p. 16).

An individual likely becomes motivated to enroll in a nursing program before so doing. Presumably, in many cases the step following initial motivation may be investigating nursing as a career.

\section{CAREER EXPLORATION}

A number of components are involved in motivating individuals to seek career paths. David Blustein defines career exploration: 
Career exploration has generally been defined as those activities in which individuals seek to assess themselves and acquire information from the external environment in order to facilitate the decision-making, job entry, and vocational adjustment processes (Blustein 1988, p. 346)

Evidence has indicated that intrinsic motivation is responsible for many behaviors, including exploratory behavior (Deci 1975, p. 28; Deci and Ryan 1985, pp. 13-18). Career exploration may emerge from a natural, pervasive desire to seek out new information. Blustein found that the most important predictors of career exploration are intrinsic sources of motivation such as the desire to learn about oneself and the environment (Blustein 1988, p. 354). Extrinsic influences such as the need to declare a major in college, select a training program, or to obtain employment can also elicit exploratory behavior. Age and gender are related to both motivational orientations and career exploration (Blustein 1988, pp. 346,351). There are virtually unlimited influences on motivation. Presumably, life experiences and other demographic variables, in addition to age and gender, affect motivations. For example, an individual whose mother has died of cancer may be motivated to enter nursing school out of a desire to help others, to combat disease, or due to a host of other motives derived from this event.

COMMITMENT

Assessing motivations for choosing a career is complex 
and fraught with difficulties. This is also the case when assessing commitment to a potential career. Commitment can be defined as the pledging or binding of oneself; as the dedicating of oneself to a course of action (Kiesler 1971, p. 26). Commitments involve generalized cultural expectations which provide penalties for those who break them (Becker 1960, pp. 36). Commitment often involves making a decision with regard to some particular line of action which has consequences for other interests and activities not necessarily related to it, even if the individual is unaware of the formation of the commitment. A commitment may be arrived at gradually without the person realizing when the commitment was actually made.

Disagreement exists about the very definition of commitment. By any definition, however, nursing students do make a commitment upon entrance into a nursing program. They commit up to five years of their time and a good deal of money to receive training. They would be both financially and socially penalized for dropping out.

ROLE

The term "role," derived from the theater, was adopted to describe the behavioral enactment of a status (a collection of rights and duties) occupied by a person (Znaniecki 1965, p. 202; Ickes and Knowles 1982, p. 7) . A role is the "dynamic aspect of status..." (Linton 1936, p. 
12). The concept of role has its sociological roots in the works of Cooley and Mead who focused on the individual's representation of his or her own self (Znaniecki 1965, p. 202).

Mead believed that roles are social objects which are stable and objectively real features of the social structure. Virtually everyone recognizes some aspect of the role of "nurse" and will at some point in their life utilize the services of a nurse due to illness or injury. This makes the role of a nurse important to everyone and especially to aspiring nurses who may well be committing a lifetime to this role. One goal of this thesis is to determine how nursing students recognize and understand the role of a nurse. In order for nursing schools to train committed nurses it is important to understand if students are aware of the role for which they are being trained.

A single role is often ambiguous, complex, and incongruent; sometimes leading to incompatibility within the role (Ickes and Knowles $1982, \mathrm{p} .7$ ). Intra-role conflict may occur if an individual perceives that others hold incompatible expectations for him or her as the possessor of a single status (Gross, Mason, and McEachern 1964, pp. 248-249). This may have bearing on understanding students' conceptions of the role of a nurse. Newly. trained nurses may experience intra-role conflict if their conception of the nurse's role does not agree with what is 
demanded from them.

According to Talcott Parsons, roles are templates for given positions in a system. These templates are enforced by the role partners of the one who holds the role (Ickes and Knowles 1982, p. 34). Presumably student nurses learn from their instructors how to match a template in order to assume the proper role of a nurse.

\section{PREVIOUS RESEARCH}

Prior research addressing the four question areas described previously in the problem statement provided the base upon which this study was constructed. Previous research will be compared with the findings of this study. Comparison between the results of previous studies and the results of this research will illuminate change involving both student nurses and nursing schools.

The first definitive comprehensive studies of student nurses were completed in the late 1950's and early 1960's when nursing was exclusively the domain of women. The following is an overview of the demographic backgrounds and life experiences of some of these students.

\section{Demographics and Iife experiences}

The first question considered in this thesis involves a straight-forward investigation of the demographic makeup and life experiences of contemporary initiates to nursing school. Although this information will not be nationally 
representative, it is nonetheless important from an exploratory perspective when considering contemporary students' motivations for entering nursing programs. This information will be compared with that gained from a $1960^{\prime} \mathrm{s}$ study.

Fred Davis, Virginia Olesen, and Elvi Whittaker studied forty-nine students who entered a baccalaureate nursing program in 1960. The class averaged nineteen years of age and was predominately Caucasian; only five were of other racial or ethnic categories. Almost all were from Protestant, white collar, middle class, and educated family backgrounds (Olesen and Whittaker 1968, pp. 3,20,83) . These data allow a qualitative reference when comparing the motivations and conceptions of the nursing role as held by these students and the students queried in this study.

The demographics of student nurses have changed since the aforementioned study. An aging population which is remaining healthy, increased occupational mobility, and other social changes have led individuals in their thirties and forties to change careers and return to school. The percentage of all college students age twenty-five and older grew from thirty-three to thirty-nine between 1974 and 1988 (Nursing Data Review 1993, p. 7). The median age of 1990 nursing school graduates was thirty-one years (Holtzclaw 1983, p. 451).

In addition to older students, increasing numbers of 
men have been entering and graduating from nursing programs. In 1978 five percent of all nursing students were men, by 1991 ten percent were men. By 1992 twelve percent of all new enrollees to nursing school were men (Moses and Roth 1979, p. 1745; Nursing Data Review 1993, p. 23 ; Nursing Datasource 1993, p. 5). The larger numbers of men in nursing programs likely corresponds with changing student perspectives. This is important when considering motivations and role conceptions of nursing students.

In addition to more older and male students, increasing numbers of part-time students are enrolling both in higher education in general and in nursing school. From 1980 to 1990 the percentage of college students who were part-time increased from forty-one to forty-three. By 1992 approximately thirty percent of all baccalaureate nursing students were part-time. Many of these part-time students are registered nurses who are returning to school to acquire baccalaureate degrees (Nursing Data Review 1992 , p. 7 ; Nursing Datasource 1993, p. 14). The increase in parttime nursing students reflects the increase in older students who already have jobs or careers.

\section{Student Motivations}

The second question area investigated involves motivations for enrolling in nursing school. In 1963, sociologist Fred Davis published a report in which it was indicated that the majority of nursing students did not 
enroll to establish a career in medical care. He found that most nursing students saw nursing as a type of life insurance should marriage and having a family not occur (Davis 1972, p.45). None of the thirty-eight students that Davis followed throughout nursing school were married at the time of entry into nursing school (eleven of the original forty-nine students did not complete the program). Twenty were married three years later by the time of graduation and ten of the remaining students indicated that they wished to marry in the next year or two. Finally, five maintained that they would like to marry several years later after gaining some independence (the marriage plans of the remaining three students is not known).

Davis found that none of the students perceived themselves as having a primary commitment to a professional career. By the third year, Davis found that "... a veritable marital sweepstakes gripped the class..." (Davis 1972, pp 45-46). It is likely that current motivations to pursue nursing are different due in part to the larger number of older and male students (Nursing Datasource 1992, pp. 19,21 ; Nursing Datasource 1993, p. 18 ; Nursing Data Review 1993, pp. 21,23). It is expected that many contemporary students are already married and not looking for a spouse. Additionally, the changing role of women in society has probably contributed to changes in motivations to study nursing. 
Davis also reported that nursing was an occupation primarily entered by middle class women who would have to balance conflicting roles such as companion, sexual partner and mother (Davis 1972, p. 11). Additionally, in 1960, over two-fifths of American general duty hospital nurses were part-time employees (United states Department of Labor 1960, p. 29). These findings do not suggest a view of nursing as a career or profession, but rather as a temporary job or as a means to supplement income. Davis, olesen, and Whittaker described the young women entering nursing schools in the 1960's as:

$$
\begin{aligned}
& \text {.. conventionally oriented... much more heavily } \\
& \text { interested in traditional feminine life goals than in } \\
& \text { career pursuits and reluctant to make more than } \\
& \text { incidental concessions toward professional } \\
& \text { involvement. }
\end{aligned}
$$

They found that this outlook remained in place throughout nursing school, and in some cases, solidified over the course of the students' education. These women were not drawn to nursing primarily for reasons of social mobility or in response to a sense of religious calling, the traditional motivational stereotypes (Davis, olesen, and Whittaker 1968, p. 159; Davis 1972, p. 12).

Many contemporary students have withdrawn from established careers to pursue nursing, and bring organizational knowledge and experience to nursing (Holtzclaw 1983, pp. 451-452). It is also likely that these students have motivations and goals different from 
those of traditional students who were recent high-school graduates.

With shifted demographics, increased tuition, and increased difficulty of entrance to nursing programs (Nursing Data Review 1993, pp. 17-23; Nursing Datasource 1993, pp. 10,18 ) it is likely that students' motivations have shifted to embrace a more professional ideology. When the aforementioned factors are combined with a relative lack of current research (Kersten, Bakewell, and Meyer 1991, p. 30) this makes a study of motivational factors for entering nursing programs a potentially valuable contribution to understanding nursing education. It may also provide modest insight into issues of professional education in general.

Through a series of surveys in the late 1950's, Kenneth Benne and Warren Bennis found that although nurses felt that the "ideal nurse" goes into nursing for idealistic reasons, most nurses entered the field for more practical reasons (Benne and Bennis 1959, p. 198). Perhaps many nurses felt that one should become a nurse out of a desire to care for the sick and to alleviate suffering, but they often had more practical goals such as job security and income potential.

In 1989, Stevens and Walker surveyed $641 \mathrm{high}$ school seniors regarding reasons why they might or might not choose a career in nursing. Some of the primary reasons 
given for choosing a career in nursing were a desire to help people, to do important work, and to work with a variety of people in an exciting setting. stevens and walker further concluded that knowing a nurse personally, caring for someone who was seriously ill, having a family member who was a nurse, or living with someone who was seriously ill, were all significantly associated with the students' indications that they would choose nursing as a career (Stevens and walker 1993, p. 16). While this provides some insight into the motivations of high school students, increasing numbers of entering nursing students are older, more mature individuals, who may have different motivations (Holtzclaw 1983, pp. 451-453; Nursing Datasource 1992, p. 19).

The aforementioned studies focused on the motivations of female student nurses because the overwhelming majority of applicants to nursing programs were women. Several studies, however, have focused on men, among them Reg williams study of 273 male nursing students in thirty-two baccalaureate nursing programs in the Western United States (Williams 1973, p. 520). Williams found that most of the male students came from middle-class backgrounds and were more likely than female students to be older and married. He surveyed the students concerning the most influential persons in their decisions to choose nursing as an occupation. Friends were most influential with high school 
guidance counselors playing an insignificant role.

When asked what reasons had been important in influencing them to enter nursing, eighty-one percent of the students indicated that "it provides an opportunity to help people." sixty-five percent responded "it provides a steady income." Thirty-six percent responded "opportunities for advancement to administrative positions are good." Williams narrowed his inquiry and found specifically that the most influential factor in prompting interest and in finalizing the decision to enter a nursing program was previous association with health care facilities (Williams 1973, p. 522). These data indicate that a considerable number of male student nurses were aspiring to administrative positions, demonstrating that this had become a part of the male student conception of the role of a nurse. The most frequently cited reason for enrolling in a nursing program, however, was to provide an opportunity to help people, which is consistent with the findings of studies of female nursing students (Kersten, Bakewell, and Meyer 1991).

Contemporary studies indicate that nursing students still identify nursing with caring. Caring can have numerous meanings; for nurses it likely includes helping, giving care and comfort, nurturing, serving, supporting, and sharing (Williams 1973, p. 522; Kersten, Bakewell, and Meyer 1991, p. 31). Some believe that in the 1980's 
nursing has moved too far from its caring traditions and an attempt should be made to reestablish caring as "the moral base of practice" (Sullivan, Langley and Deane 1994, p. 7). The importance of caring to nursing is an issue yet to be resolved.

\section{Conceptions of the nurse's role}

The third question area to be investigated concerns students' conceptions of the role of a nurse. Previous research by Davis and Olesen included a study in which entering students were asked to rank four different female roles according to the relative emphasis they would assign each if they could arrange their lives to be ideal. These four roles were home and family, work and career, glamour, and community service. Approximately eighty-six percent of the sample ranked "home and family" in first place. sixtyone percent put "work and career" in second place. Twentysix percent relegated "work and career" to third or fourth place, while only twelve percent put it in first place (Davis and Olesen 1972, p. 13). It is apparent that these students did not conceive of the role of a nurse as involving a career which would take priority in their lives. The students' perspective does not entail nursing as a profession with its sense of "calling."

In 1993 Grossman and Northrop reported that high school students perceived the nursing role as allowing them to care for people, work very hard, work with their hands, 
and to work with high-tech equipment (Grossman and Northrop 1993, p. 158). These conceptions held by contemporary students seem appropriate to a view of nursing as a trade or helping occupation, but it does not allude to a professional conception of nursing.

The students surveyed in the stevens and walker study believed that nurses primarily followed doctors' orders, made a lot of money, and that nursing was a career for intelligent people. Most believed that nurses made their own decisions, had many opportunities for promotions and could always obtain employment (Stevens and walker 1993, p. 14). This perspective of nursing is consistent with a view of nursing as a career with advancement opportunities, if not quite a profession.

In a 1993 study, Alice Kiger found that initiates to nursing programs viewed nursing not just as a job, but as either a profession, career, vocation, or calling. They believed that it offered prospects for promotion and specialization, that it was varied and satisfying work, and that it was a respected occupation. Students felt good about saying they were training to be a nurse and that they were going to be in an honorable helping occupation (Kiger 1993, p. 311).

Entering nursing students pictured nurses as working in an adult medical or surgical, "Nightingale-style" open ward. The students pictured nurses as female. They 
imagined nursing as taking place in a formal and disciplined environment: nurses wore uniforms and caps, and generally cared for bed-ridden patients. Kiger reported that students were unaware of the origins of many parts of their perspectives on nursing (Kiger 1993, pp. 310-311). The students investigated in the aforementioned studies conceived of the role of a nurse as demanding, rewarding and secure. The $1960^{\prime}$ s students did not perceive nursing as a profession and did not see it as the most important priority in their lives. students in the contemporary studies, however, included professional aspects in their conceptions of the role of a nurse. Many believed that nurses were intelligent, made their own decisions, and that nursing offered opportunities for promotion and specialization. Although the students recognized the less professional aspects of nursing, such as following doctors' orders and working with their hands, they would likely define nursing as a profession.

\section{Comparison of expectations, ideals, and reality}

The final question area under investigation involves how the expectations of entering students compare with the realities of nursing and with the students' views of ideal nursing. First, there is no sharp disjunction between conceptions during nursing training and realities of nursing practice because nurses spend a good deal of their training in actual nursing environments, thus undergoing 
socialization. Nonetheless, discord between expectations and reality appears to be present both for graduating nurses and for entering students.

Some of this discord may be due to the diversity of nursing education programs. Three general types of programs exist. First, one of the earliest types of nursing education to develop was the diploma program. This is generally a three year hospital run school which qualifies students solely for the registered nurse license. A second type is the associate degree program which involves two years of training at a junior or community college. Finally, the baccalaureate program, four to five years in length, is offered by colleges or universities and grants a bachelor's degree (Davis, olesen, and whittaker 1966, p. 138). The differences between these programs makes it likely that the expectations of graduating nurses will vary widely and perhaps differ from the reality of nursing.

Disagreement between student nurses' conceptions of nursing and the reality of nursing may also be related to institutional incongruity. Davis, Olesen, and Whittaker found structural discontinuity between collegiate nursing education and hospital based nursing. In the 1960's when the numbers of graduates from baccalaureate programs grew rapidly, it was reported that:

[with some few exceptions] American hospitals make no institutionalized distinction whatever-either in 
rank, salary, or job specification-between the beginning collegiate and the beginning diploma nurse (Davis, Olesen, and Whittaker 1966, p. 167). Hospitals did not readily accommodate concepts and professional ideals taught in university nursing schools (Davis, Olesen, and Whittaker 1966, p. 168). One would expect a significant change in contemporary hospital policy because of the increase in nurses with baccalaureate degrees and the corresponding decrease in nurses with diplomas.

In 1960, eighty-four percent of graduating nurses completed a diploma program while fourteen percent completed a baccalaureate program and three percent finished an associate degree program. In 1976 only twentysix percent of graduating nurses completed a diploma program while twenty-nine percent finished a baccalaureate program and forty-five percent completed an associate's degree program. By 1991, twenty-seven percent graduated from a baccalaureate school while only nine percent graduated from diploma schools. The remaining sixty-five percent obtained associate degrees (United states Department of Health, Education and Welfare 1973, p. 221; United States Department of Health, Education and Welfare 1977, p. 175; Nursing Data Review 1993, p. 24). The dramatic shift from diploma schools to associate degree programs is shown in Figure 1. An incongruity from Kiger's study involved the 


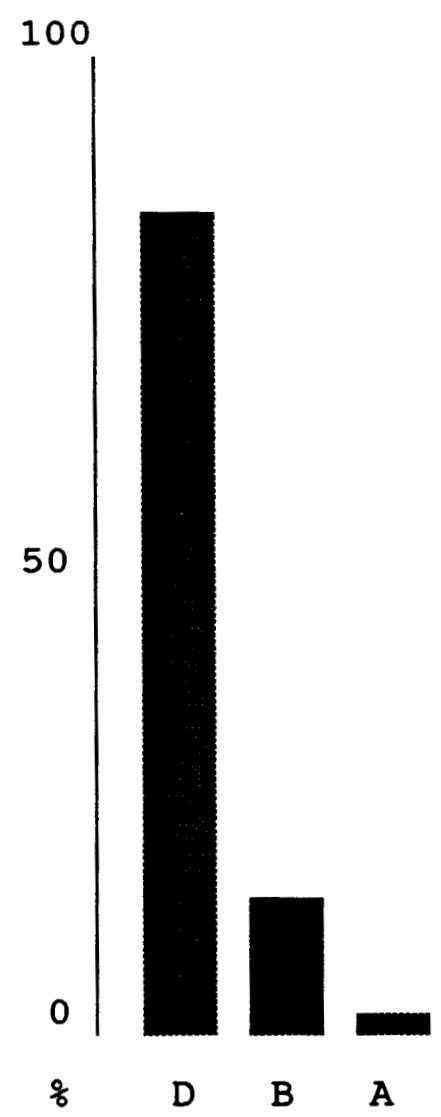

1960
$D=$ DIPLOMA PROGRAM

B = BACCALAUREATE PROGRAM

$A=$ ASSOCIATE DEGREE PROGRAM

Figure 1. Percentage of nursing students enrolled in diploma, baccalaureate, and associate degree programs in 1960, 1976, and 1991.

perceived helping role of the nurse. Many of the students indicated that they initially pictured nurses as doing everything possible to help the patient. They discovered in actual practice, however, that nurses had to encourage patients to help themselves (Kiger 1993, p. 314). This represents a difference, albeit modest, between what students expect of nursing and the reality of nursing. students may find a disparity between their image of nursing and a particular type of nursing. For example, in 
Kiger's study one student nurse found psychogeriatric nursing to be rote and humorless work, not at all what she had imagined. In this case the student could simply specialize in another area. If, however, disjunctions between expectations and reality are present for all nursing areas, as it was for one student in the study, he or she may seek alternative employment in a non-medical field (Kiger 1993, pp. 314-315).

Disagreement between ideals and nursing realities is also apparent for graduate nurses. In their late 1950's study, Benne and Bennis indicated that discord was present between nurses' ideals concerning the physician/nurse relationship and the reality of the relationship. The study sample consisted of ninety nurses working in outpatient departments. Nurses were shown a cartoon containing a physician, a nurse, and a patient. The physician was addressing the nurse as follows, "Nurse, could you ...?" The nurses in the study were asked to complete the sentence and also to indicate what the cartoon nurse was thinking. The most common sentence completions were "prepare patient for examination or treatment," "obtain equipment, reports or records," and "assist the doctor with examination or treatment" (Benne and Bennis 1959, p. 197)

The responses indicating what the nurse was thinking demonstrated discord between reality and the ideal nursing 
conditions desired by nurses. Most of the thoughts which the nurses ascribed to the cartoon nurse fell into the category of "denying or contradicting the doctor's order, or showing hostility to him." Many of the nurses indicated that the cartoon nurse was likely supportive of the doctor, but had thoughts such as "certainly, but he looks capable of doing this himself" (Benne and Bennis 1959, p. 197). This report suggests that nurses experience discord between reality and their ideal expectations. One might expect even greater discord among student nurses as they have yet to undergo complete socialization into the nursing role.

In his 1960 report of discrepancies between the perceptions of the ideal role of a nurse and the realities of practice among 296 student and graduate nurses, Ronald Corwin maintained that there is a basic dilemma in nursing. While nurses professed to prefer contact with patients, they were rewarded for values and skills which did not require it. Corwin writes:

Professionalization has shifted attention and energy from the patient to a maze of technical duties and to a range of activities designed to raise professional standards, which include committee work, reading and contributing to professional journals, and attendance at meetings (Corwin 1960, p. 607).

Corwin reported conflict between bureaucratic and professional conceptions of the role of a nurse. He described the bureaucratic conception as involving specialization in administrative routine, as stressing categorical and routine elements of nursing. The 
professional conception involves concern for a body of knowledge, with the goal of maintaining standards and values (Corwin 1960, p. 606).

Both bureaucratic and professional conceptions of nursing can be held at the same time by an individual, but this may lead to conflict. Students or nurses are confronted with intra-role conflict (Gross, Mason, and McEachern 1964, pp. 248-249) as they discover that others may have conflicting expectations for them. This conflict arises primarily from a disagreement between schools and hospitals concerning allegiance to professional and bureaucratic principles. This discrepancy between expectations and reality is likely dependent upon the training received by student nurses, rather than the preconceptions they bring to their training (Corwin 1960, p. 607). Students, however, may possess some of these professional and bureaucratic ideals before they have undergone socialization in nursing school due to prior occupations and education.

Disagreement exists both between expectations and the realities of nursing and between expectations and ideals. Although nursing inevitably does not prove to be precisely what was expected by students, the discongruities do not appear large. One purpose of this inquiry is to ascertain agreement or lack thereof between expectations, ideals, and reality. 
CHAPTER III

\section{METHODOLOGY}

\section{INTRODUCTION}

The best sources of information about the motivations and conceptions of student nurses are the students themselves. A questionnaire design was chosen as the simplest and most practical method to ascertain the demographic backgrounds, motivations, and role conceptions of student nurses. Three schools of nursing were chosen for comparative reasons. Two of the schools (community colleges) offer an associate's degree in nursing as the most advanced nursing degree. The third school offers baccalaureate, master's and doctoral degrees in nursing.

The survey was administered only to first year students studying to prepare for basic licensure as a registered nurse. These particular schools were chosen first, because all three offer registered nurse training, and second, because the composition of the students in the two types of schools was expected to be different. The latter was expected because the two community colleges offer only associate degree programs and are not associated with a hospital or medical school. The third school offers more advanced degrees and is associated with a hospital. 
Also, admission to the baccalaureate program is more difficult than is admission to the community college programs.

The survey instrument was designed to be easily completed in ten to fifteen minutes in a classroom. Questionnaires from previous studies were utilized as models in designing questions. The questionnaire was pretested on a number of individuals including pre-nursing students and a graduate student in sociology familiar with survey design and construction (the questionnaire is included in full in Appendix A).

The student nurses completed the questionnaires in classrooms. Of 143 students surveyed, sixty-eight were enrolled in the four-year baccalaureate program and seventy-five were enrolled in the community college programs. An attempt was made to survey all the first year students in each school, but inevitably some students were missed or did not return the questionnaires. Participation was voluntary and it was explained that refusal to participate would in no way affect a student's course grade or relationship with the school. In order to maintain anonymity, the completed surveys were collected by the instructor or compiled in a stack and then handed in one group to the researcher. The research method and questionnaire were approved by the Human Subjects Research Review Committee at Portland state University (see Appendix 
B for the approval request and approval).

The completed surveys were coded and entered into a database which was then analyzed using the statistical Package for the Social Sciences for Personal Computers (SPSS/PC).

\section{LIMITATIONS AND ASSUMPTIONS}

This research is bounded by a number of limitations and based upon several assumptions. First, the research was conducted in three nursing schools in or around Portland, oregon. The schools were not chosen randomly, but were selected to include a variety of students. Consequently, the results of this research can be generalized only with caution to nursing students in other programs. Second, the students were nearing the end of the first year of their respective nursing programs. Thus, they have undergone some socialization into the role of a nurse. This must be considered when comparing students' views of the role of a nurse and the actual role of a nurse because the intent of this study is to query students early in their training.

The standardization and brevity required by survey research raises the possibility of subjects misunderstanding questions with no opportunity for clarification. In fact, students who asked about the meaning of any of the questions on the survey were told to 
answer to the best of their ability, that any attempt to explain questions would jeopardize the uniformity of the research.

This research is based upon several assumptions. First, it is assumed that motivations and role conceptions can be adequately measured through the use of a survey instrument. Second, any survey research is faced with the possibility of less than honest answers. subjects may not always be truthful. For example, they may be ashamed of their true motivations and want to appear more admirable or noble than they actually are. Finally, subjects may not always be aware of the inaccuracy of their responses. They may intend to indicate the correct responses, but may be unaware that their responses actually addresses a different question. For example, when a subject is asked what type of nurse he or she plans to be, the subject may instead indicate the type of nurse that he or she wants to be.

\section{INTER-CODER RELIABILITY}

In order to evaluate the reliability of the coding of the questionnaires and the subsequent entering of the results into a computer database, a random sample of ten questionnaires with a code-sheet and the corresponding database were given to a Portland State University sociology graduate student familiar with research methodology and design. Each questionnaire has 106 
variables resulting in a total of 1060 individual codings for the ten questionnaires. The codes on the ten questionnaires were compared with the code-book and the codes that were entered in the database. Three errors in coding were found out of a possible 1060 errors, indicating an inter-coder reliability of 0.9972 or 99.72 percent. 
CHAPTER IV

ANALYSIS

INTRODUCTION

The analysis of the data from the 143 questionnaires is presented in this chapter. Information about why the students chose nursing, how they view nursing, what will be important to them as nurses, and what kinds of nurses they want to be will be presented in table form. Analysis from the questionnaires will be included in a number of tables. Some tables will present comprehensive data from all 143 questionnaires and others will contain data which are segregated by type of school for comparison. Student responses will be separated into two groups, those from the community college programs and those from the four-year baccalaureate program.

\section{DEMOGRAPHICS}

The students surveyed for this study were a somewhat diverse group. The data in Table I show that they ranged in age from nineteen to sixty-two years. The mean age was thirty-two, considerably older than the students in the Davis, olesen, and Whittaker study. Even so, the modal age was twenty-two. The difference between mean and mode was 
due to many students in their thirties and forties. Differences are also apparent when the ages of the baccalaureate students and the community college students are compared. The baccalaureate students range in age from 20 to 44 years. The mean age was 29 and the modal age was 22. The community college students range in age from 19 to 62 years. The mean age was 34 and the modal age was 28 . These data show that the community college students were older than the baccalaureate students. It is likely that more of the community college students were coming back to school from other careers and occupations.

As indicated in Table I, fifty-four percent of respondents had prior experience in a health care field. Forty-nine percent of the baccalaureate students and fiftynine percent of the community college students indicated prior experience in a health care field. The difference in experience between type of students was not great but it likely reflects the age difference between community college students and baccalaureate students.

In addition to greater numbers of older students in nursing programs today compared to the 1960's, there are also more males (see Table I). Eighteen percent of the students were male. Twenty-one percent of the community college students were male, while fifteen percent of the baccalaureate students were male. Men are enrolling in the community college programs in significant numbers, 
comprising almost a quarter of the students surveyed in the two community colleges.

The prevalence of men in the three schools was consistent with the trend in U.S. nursing schools in general. According to Nursing Datasource 1992, by 1991 approximately ten percent of U.S. student nurses were male. If the aforementioned eighteen percent is at all representative of the national average, the number of males attending nursing school has risen sharply in the last four years.

The racial or ethnic background of the students was somewhat different from the students surveyed by Davis, Olesen, and Whittaker in the 1960's. Table I demonstrates that while eighty-three percent of the students identified themselves as White and non-Hispanic, minorities were present. One percent were Native American or Alaskan Native, eight percent were Asian or Pacific Islander, two percent were Black, and two percent were Hispanic.

There was little difference in the racial or ethnic composition between the two types of colleges. Eighty-four percent of the community college students and eighty-two percent of the four-year college students were white, nonHispanics. A slight difference was apparent in the small numbers of minority students at the two types of colleges. The community colleges had two Native American or Alaskan Native students, one Black or African American student and 
no Hispanic students. The minority students at the fouryear college included two Blacks or African Americans and three Hispanics. Both types of colleges included comparable numbers of Asians or Pacific Islanders. As expected, the marital status of the students is quite different from that of the students surveyed for the Davis, Olesen, and Whittaker study. The 1960's students were predominately unmarried. In fact, only one of the forty-nine students was married at entry (Olesen and Whittaker 1968, p. 90). Table I indicates that forty-one percent of the students in this study were single and forty-four percent were married. Also, ten percent indicated that they were divorced. This is a considerable change from the $1960^{\prime}$ s students. Married students now comprise the largest category. In addition to more married students, there were also more students with children than in the 1960's school. Forty percent of the students indicated that they had children. These changes are consistent with the contemporary students being older and with more divorced individuals in today's society as a whole.

The marital status of the students varied significantly between the two types of colleges. Thirtytwo percent of the community college students were single, while fifty percent of the four-year college students were single. Additionally, fifty-two percent of the community 
TABIE I

STUDENT CHARACTERISTICS

\begin{tabular}{|c|c|c|c|c|}
\hline VARIABLE & $\begin{array}{l}\text { COMMUNITY } \\
\text { COLLEGES }\end{array}$ & $\begin{array}{l}\text { FOUR-YEAR } \\
\text { COLLEGES }\end{array}$ & ALL & COLLEGES \\
\hline MEAN AGE/YEARS & 34 & 29 & & 32 \\
\hline MODAL AGE/YEARS & 28 & 22 & & 22 \\
\hline YOUNGEST/YEARS & 19 & 20 & & 19 \\
\hline OLDEST/YEARS & 62 & 44 & & 62 \\
\hline & $8 \quad(N=75)$ & $(\mathrm{N}=68)$ & 8 & $(\mathrm{~N}=143)$ \\
\hline $\begin{array}{l}\text { PRIOR HEALTH } \\
\text { CARE EXPERIENCE }\end{array}$ & $(44)$ & $(33)$ & 54 & $(77)$ \\
\hline MALE / FEMALE & $21 / 77(16 / 58)$ & $15 / 84(10 / 57)$ & $18 / 80$ & $(26 / 115)$ \\
\hline HAVE CHILDREN & $52 \quad(39)$ & (18) & 40 & $(57)$ \\
\hline $\begin{array}{l}\text { NATIVE AMER/ } \\
\text { ALASKAN NATIVE }\end{array}$ & (2) & (0) & 1 & (2) \\
\hline $\begin{array}{l}\text { ASIAN / PACIFIC } \\
\text { ISLANDER }\end{array}$ & $(6)$ & (5) & 8 & (11) \\
\hline $\begin{array}{l}\text { BLACK, NON- } \\
\text { HISPANIC }\end{array}$ & (1) & (2) & 2 & (3) \\
\hline HISPANIC & $(0)$ & (3) & 2 & (3) \\
\hline $\begin{array}{l}\text { WHITE, NON- } \\
\text { HISPANIC }\end{array}$ & $(63)$ & $(56)$ & 83 & $(119)$ \\
\hline SINGLE & $(24)$ & (34) & 41 & (58) \\
\hline MARRIED & $(36)$ & $(27)$ & 44 & $(63)$ \\
\hline DIVORCED & $(11)$ & $(3)$ & 10 & $(14)$ \\
\hline \multicolumn{5}{|l|}{$\begin{array}{l}\text { HIGHEST DEGREE } \\
\text { OBTAINED }\end{array}$} \\
\hline GED & (2) & (0) & 1 & (2) \\
\hline $\begin{array}{l}\text { HIGH SCHOOL } \\
\text { DIPLOMA }\end{array}$ & (8) & (1) & 6 & (9) \\
\hline BACHELOR'S & $(14)$ & $(30)$ & 31 & $(44)$ \\
\hline ADVANCED DEGREE & (1) & (4) & 4 & (5) \\
\hline
\end{tabular}

Percentages for each category do not necessarily add up to 100 due to missing responses, responses which do not fit into any category, and rounding. 
college students had children, while only twenty-seven percent of the four-year college students had children. The educational backgrounds of the students were diverse. Table I indicates that thirty-one percent had received a bachelor's degree and four percent had received an advanced degree. A striking difference is apparent between the community college students and the baccalaureate students. Fifty percent of the four-year college students had acquired a bachelor's or advanced degree while only twenty percent of the community college students had done so (the categories "bachelor's degree" and "advanced degree" in Table I are combined).

These data show that many of the students had considerable education prior to enrolling in a nursing program. It was not expected that such a large percentage of the baccalaureate students would have bachelor's degrees prior to enrolling in the program. One possible explanation is that competition for entrance has increased enough that the school is able to choose mostly educated students.

As expected, the demographic characteristics of these students are quite different from those of Davis', olesen's and Whittaker's survey respondents. It appears that contemporary nursing students are a much more diverse group than were students in previous decades. 
MOTIVATIONS TO STUDY NURSING

students in the current study were much more likely to perceive nursing as a life-long career than were the students queried by Davis, Olesen, and Whittaker in the 1960's. As shown in Table II the overwhelming majority (eighty-nine percent) indicated that they intended to make nursing a life-long career. Additionally, seventy-one percent indicated an intention to pursue nursing full-time with seven percent planning to work full-time for a period and then work part-time. These results indicate that these students generally did not see nursing as a transitory job or temporary position.

Also, shown in Table II is general agreement between

TABLE II

STUDENTS' FUTURE WORK INTENTIONS, CONTRASTED BY TYPE OF COLLEGE

$\mathrm{N}=75$ FOR COMMUNITY COLLEGES, $\mathrm{N}=68$

FOR FOUR-YEAR COLLEGES, AND COMBINED $\mathrm{N}=143$

\begin{tabular}{|c|c|c|c|c|c|c|}
\hline \multirow[t]{2}{*}{ FACTORS } & \multicolumn{2}{|c|}{$\frac{\text { COMMUNITY }}{\text { COLLEGES }}$} & \multicolumn{2}{|c|}{$\begin{array}{l}\text { FOUR-YEAR } \\
\text { COLLEGE }\end{array}$} & \multicolumn{2}{|c|}{ ALL STUDENTS } \\
\hline & 8 & $(n)$ & 8 & $(\mathrm{n})$ & 8 & $(n)$ \\
\hline $\begin{array}{l}\text { INTEND TO MAKE } \\
\text { NURSING A LIFE-LONG } \\
\text { CAREER } \\
\end{array}$ & 92 & (69) & 85 & (58) & 89 & (127) \\
\hline $\begin{array}{l}\text { INTEND TO WORK FULL- } \\
\text { TIME }\end{array}$ & 69 & (52) & 74 & $(50)$ & 71 & $(102)$ \\
\hline $\begin{array}{l}\text { INTEND TO WORK FULL- } \\
\text { TIME FOR A PERIOD AND } \\
\text { THEN WORK PART-TIME } \\
\end{array}$ & 5 & (4) & 9 & (6) & 7 & (7) \\
\hline $\begin{array}{l}\text { INTEND TO WORK PART- } \\
\text { TIME SOON AFTER } \\
\text { GRADUATION }\end{array}$ & 35 & $(26)$ & 21 & (24) & 28 & $(40)$ \\
\hline
\end{tabular}


community college and baccalaureate students concerning their work intentions. The only significant difference involves those students intending to work part-time soon after graduation. Thirty-five percent of the community college students indicated that they intended to work parttime soon after graduation while only twenty-one percent of the baccalaureate students did so.

student nurses still appear to be motivated by a desire to help others in that seventy-nine percent of the respondents indicated that the desire to help people was very important in influencing their decision to study nursing (see Table III). A full ninety-seven percent of the respondents indicated that the desire to help people was at least moderately important in their decision (categories "very" and "moderately" in Table III were combined). The desire to help people appears to be the one common outstanding factor which influenced the students to study nursing.

The desire to do important work and the opportunity to work with a variety of people were also important factors in students' decisions to study nursing. Sixty-three percent indicated that the desire to do important work was a very important factor in their decision while fifty-nine percent indicated that the opportunity to work with a variety of people was a very important factor.

In his 1963 report Fred Davis indicated that many 
TABLE III

IMPORTANCE OF FACTORS INFLUENCING THE DECISION TO STUDY NURSING

$\mathrm{N}=143$

\begin{tabular}{|c|c|c|c|c|c|c|c|c|c|}
\hline \multirow[t]{2}{*}{ FACTORS } & VERY & \multicolumn{2}{|c|}{ MODERATE } & \multicolumn{2}{|c|}{ SOMEWHAT } & \multicolumn{2}{|c|}{ NOT VERY } & \multicolumn{2}{|c|}{ NOT/ALL } \\
\hline & $8 \quad(n)$ & 8 & $(n)$ & 8 & $(\mathrm{n})$ & 8 & $(n)$ & 8 & $(n)$ \\
\hline $\begin{array}{l}\text { DESIRE TO } \\
\text { HELP PEOPLE }\end{array}$ & 79 (113) & 18 & $(25)$ & 4 & (5) & & & & 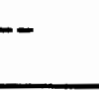 \\
\hline $\begin{array}{l}\text { DESIRE FOR } \\
\text { IMPORTANT } \\
\text { WORK }\end{array}$ & $(90)$ & 27 & $(38)$ & 9 & (13) & & & & - \\
\hline $\begin{array}{l}\text { WILL PROVIDE } \\
\text { RESPECT }\end{array}$ & $46(66)$ & 31 & $(44)$ & 17 & $(24)$ & 5 & (7) & 1 & (1) \\
\hline GOOD SALARY & $24 \quad(34)$ & 44 & $(63)$ & 23 & (33) & 6 & (9) & 3 & (4) \\
\hline $\begin{array}{l}\text { GOOD / FLEXIBLE } \\
\text { HOURS }\end{array}$ & 23 (33) & 26 & $(37)$ & 28 & $(40)$ & 18 & $(25)$ & 6 & (8) \\
\hline JOB SECURITY & $23 \quad(33)$ & 34 & $(49)$ & 29 & $(41)$ & 11 & $(15)$ & 4 & $(5)$ \\
\hline $\begin{array}{l}\text { NURSING IS } \\
\text { EXCITING }\end{array}$ & $48 \quad(68)$ & 34 & $(48)$ & 14 & $(20)$ & 1 & (2) & 1 & (1) \\
\hline $\begin{array}{l}\text { WORK WITH A } \\
\text { VARIETY OF } \\
\text { PEOPLE }\end{array}$ & $(85)$ & 27 & $(39)$ & 8 & (11) & 4 & (6) & 1 & (1) \\
\hline $\begin{array}{l}\text { OPPORTUNITY } \\
\text { TO MEET A } \\
\text { LIFE-PARTNER }\end{array}$ & (4) & 4 & (5) & 11 & (15) & 11 & $(15)$ & 71 & (101) \\
\hline $\begin{array}{l}\text { OPPORTUNITY } \\
\text { TO BE A } \\
\text { LEADER }\end{array}$ & $(23)$ & 31 & $(44)$ & 30 & (43) & 12 & (17) & 8 & (12) \\
\hline
\end{tabular}

Percentages in each category do not necessarily add to 100 due to rounding and missing responses.

student nurses saw nursing as a form of "life insurance" should getting married and having a family not occur (Davis 1966, p. 40). Meeting a husband was a priority for the students and over half married while in school (Davis 1972, pp. 45-46). In contrast, the students surveyed for this study clearly indicated that they did not enter nursing 
school to get married or to meet a mate. A full seventyone percent of the respondents indicated that the possibility of meeting a life-partner had no influence at all on their decision to study nursing.

Nonetheless, this influence is significant for a small percentage of the students. As shown in Table III, eighteen percent responded that the opportunity to meet a life-partner was somewhat to very important in influencing their decision to study nursing (categories "very," "moderately," and "somewhat" in Table III were combined). It seems clear that even if this were an important motivating factor for Davis', Olesen's and Whittaker's students, it clearly was not important to the students surveyed here.

Twenty-four percent responded that a good salary was a very important influence while twenty-three percent indicated that job security and good or flexible hours were very important. These practical goals were less important than any of the other factors except the opportunity to meet a life-partner and the opportunity to be a leader. The students indicated that they were motivated to pursue nursing for idealistic reasons, not for more practical goals of income and job security.

only a few differences were apparent between students in the two types of schools. Fifty-four percent of the baccalaureate students indicated that good or flexible 
hours were moderately to very important in their decision to study nursing while only forty-four percent of the community college students did so (see Table IV). Although this was not an important factor in comparison to the others, it was more important to the four-year students

TABLE IV

IMPORTANCE OF FACTORS INFLUENCING THE DECISION TO STUDY NURSING, CONTRASTED BY TYPE OF COLLEGE

$\mathrm{N}=75$ FOR COMMUNITY COLLEGES AND N=68 FOR FOUR-YEAR COLLEGE

\begin{tabular}{|c|c|c|c|c|}
\hline & COMMUNITY & COLLEGES & FOUR YEAR & COLLEGE \\
\hline FACTORS & $\begin{array}{l}\frac{\text { MODERATE- }}{\text { LY/VERY }} \\
\& \quad(n)\end{array}$ & $\begin{array}{l}\text { NOT VERY / } \\
\text { NOT AT ALI } \\
\begin{array}{ll}8 & \text { (n) }\end{array}\end{array}$ & $\begin{array}{l}\frac{\text { MODERATE- }}{\text { LY/VERY }} \\
\frac{(n)}{8}\end{array}$ & $\begin{array}{l}\text { NOT VERY } \\
\text { NOT AT ALL } \\
\begin{array}{ll}8 & (\mathrm{n}) \\
\end{array}\end{array}$ \\
\hline $\begin{array}{l}\text { DESIRE TO } \\
\text { HELP PEOPLE }\end{array}$ & 95 (71) & $0 \quad(0)$ & $99(67)$ & 0 (0) \\
\hline $\begin{array}{l}\text { DESIRE FOR } \\
\text { IMPORTANT } \\
\text { WORK }\end{array}$ & $87(65)$ & 1 (1) & $93(63)$ & 2 (1) \\
\hline $\begin{array}{l}\text { WILL } \\
\text { PROVIDE } \\
\text { RESPECT }\end{array}$ & 77 (58) & 3 (2) & 77 (52) & 9 (6) \\
\hline GOOD SALARY & 67 (50) & $11 \quad(8)$ & $69(47)$ & 7 (5) \\
\hline $\begin{array}{l}\text { GOOD / FLEX- } \\
\text { IBLE HOURS }\end{array}$ & 44 (33) & $21(16)$ & $54(37)$ & 25 (17) \\
\hline $\begin{array}{l}\text { JOB } \\
\text { SECURITY }\end{array}$ & $57(43)$ & 12 (9) & 57 (39) & 16 (11) \\
\hline $\begin{array}{l}\text { NURSING IS } \\
\text { EXCITING }\end{array}$ & $80(60)$ & $3 \quad(2)$ & $82(56)$ & $6 \quad(4)$ \\
\hline $\begin{array}{l}\text { WORK WITH A } \\
\text { VARIETY OF } \\
\text { PEOPLE }\end{array}$ & $89(67)$ & $5 \quad(4)$ & 84 (57) & 4 (3) \\
\hline $\begin{array}{l}\text { OPPORTUNITY } \\
\text { TO MEET A } \\
\text { LIFE- } \\
\text { PARTNER } \\
\end{array}$ & $5 \quad(4)$ & $73(55)$ & $7 \quad(5)$ & 90 (61) \\
\hline $\begin{array}{l}\text { OPPORTUNITY } \\
\text { TO BE A } \\
\text { LEADER }\end{array}$ & 47 (35) & 17 (13) & $47 \quad(32)$ & 24 (16) \\
\hline
\end{tabular}


than to the community college students. Additionally, ninety percent of the four-year college students, compared to seventy-three percent of the community college students, indicated that the opportunity to meet a life-partner was not very or not at all important to them. More of the four-year students strongly reject the suggestion that they may be going to nursing school to meet a life-partner, even though a smaller percentage of them are currently married (see Table I).

The survey also asked about the importance of family, friends, teachers, co-workers, and guidance counselors in the decision to study nursing. Of these categories, the most important was family, with fifty-three percent of the students indicating that family was moderately to very important in their decision to study nursing (see Table $\mathrm{V}$; categories "very" and "moderately" were combined). The next most important category was friends, with thirty-seven percent of the students indicating that friends played a moderately to very important role in their decision. The importance of friends is consistent with the aforementioned findings of william's study of male nursing students (Williams 1973, p. 522).

Both teachers and co-workers had a modest influence on the students' decisions to study nursing. Twenty-three percent of the students indicated that teachers had at least a moderate influence. The corresponding figure for 
co-workers was twenty-seven percent. It is of some interest that co-workers are a slightly more important influence than teachers and more important than guidance counselors. This reflects the high percentage of contemporary students that have had significant employment experiences, often in health care (see Table I).

Only fourteen percent of the respondents indicated that guidance counselors played a moderate to very important role which is consistent with williams' finding that high-school counselors played an insignificant role in students' decisions to attend nursing school (Williams 1973, p. 522)

In general, only slight differences were found in the importance of these categories of people between community

TABLE V

IMPORTANCE OF CATEGORIES OF PEOPLE INFLUENCING THE DECISION TO STUDY NURSING

$\mathrm{N}=143$

\begin{tabular}{|c|c|c|c|c|c|}
\hline CATEGORIES & $\begin{array}{l}\text { VERY } \\
8 \quad(n) \\
\end{array}$ & $\begin{array}{l}\text { MODERATELY } \\
8(n) \\
\end{array}$ & $\begin{array}{l}\text { SOMEWHAT } \\
8(n) \\
\end{array}$ & $\begin{array}{l}\text { NOT VERY } \\
\&(n) \\
\end{array}$ & $\begin{array}{l}\text { NOT AT ALL } \\
8 \text { (n) }\end{array}$ \\
\hline FAMILY & $28(40)$ & $25(36)$ & $15(21)$ & $14(20)$ & $16(23)$ \\
\hline FRIENDS & $10(14)$ & $27(38)$ & $25(35)$ & $18(26)$ & $19(27)$ \\
\hline TEACHERS & $7(10)$ & $16(23)$ & $24(34)$ & $22(31)$ & $29(41)$ \\
\hline CO-WORKERS & $11(15)$ & $16(23)$ & $18(26)$ & $22(31)$ & $32(45)$ \\
\hline $\begin{array}{l}\text { GUIDANCE } \\
\text { COUNSELORS }\end{array}$ & 3 (4) & 11 (15) & 11 (16) & $20(29)$ & $52(75)$ \\
\hline
\end{tabular}

Percentages do not necessarily add to 100 due to rounding and missing responses. 
college students and four-year baccalaureate students. Fifty-three percent of both the community college students and the baccalaureate students felt that family was moderately to very important in their decision to attend nursing school (see Table VI). Additionally, thirty-two percent of the community college students indicated that co-workers were moderately to very important in their decision, while twenty-one percent of the baccalaureate students were in the same category. The latter difference may be due to the higher percentage (fifty-nine versus forty-nine) of community college students compared to

TABLE VI

IMPORTANCE OF CATEGORIES OF PEOPLE INFLUENCING

THE DECISION TO STUDY NURSING, CONTRASTED BY TYPE OF COLLEGE

$N=75$ FOR COMMUNITY COLLEGES

$\mathrm{N}=68$ FOR FOUR-YEAR COLLEGE

\begin{tabular}{|c|c|c|c|c|}
\hline & COMMUNITY & COLLEGES & FOUR YEAR & COLLEGE \\
\hline \multirow[t]{2}{*}{ CATEGORY } & $\frac{\text { MODERATE- }}{\text { LY/VERY }}$ & $\frac{\text { NOT VERY } /}{\text { NOT AT ALL }}$ & $\frac{\text { MODERATE - }}{\underline{\text { LY } / \text { VERY }}}$ & $\frac{\text { NOT VERY / }}{\text { NOT AT ALL }}$ \\
\hline & $(n)$ & $8 \quad(n)$ & $(n)$ & $8 \quad(n)$ \\
\hline FAMILY & $53 \quad(40)$ & $29 \quad(22)$ & $(36)$ & (21) \\
\hline FRIENDS & $36 \quad(27)$ & $29 \quad(22)$ & (25) & $46 \quad(31)$ \\
\hline TEACHERS & $25 \quad(19)$ & $40 \quad(30)$ & $21 \quad(14)$ & $(42)$ \\
\hline CO-WORKERS & $32 \quad(24)$ & $40 \quad(30)$ & (14) & $(46)$ \\
\hline $\begin{array}{l}\text { GUIDANCE } \\
\text { COUNSELORS }\end{array}$ & $19(14)$ & $65 \quad(49)$ & (13) & $(55)$ \\
\hline
\end{tabular}

Percentages do not necessarily add to 100 due to rounding, missing responses and the omission of the category "somewhat." 
baccalaureate students who had prior health care experience (see Table I).

Personally knowing a nurse was a factor in the decision to study nursing for fifty-six percent of the respondents (see Table VII). It is not known, however, whether or not respondents knew a nurse before becoming interested in nursing or whether they sought out nurses after initially becoming interested. Additional research would be needed to resolve this question.

Additional relationships and events were factors in the decision to study nursing. Having a nurse in the family was a factor for thirty-three percent of the students. Taking care of a seriously ill person was a factor in twenty-seven percent of the students' decisions. Living with a seriously ill person or the death of someone close were less important (see Table VII).

Nursing was traditionally viewed as a calling and is still viewed this way by some (Elzinga 1990, p. 155). The students in this study also agree that nursing is a calling in that sixty-six percent indicated that "a sense of a calling to serve others" was a moderately to very important factor in their decision to study nursing (see Table VIII; categories "very" and "moderately" were combined).

Comparatively few of the students placed importance on medical administration as a motivating factor to study nursing. Only twenty percent of the respondents indicated 
TABLE VII

INDIVIDUALS OR EVENTS HAVING INFLUENCE ON THE DECISION TO STUDY NURSING

N=75 FOR COMMUNITY COLLEGES, N=68 FOR FOUR-YEAR COLLEGE, AND COMBINED $N=143$

\begin{tabular}{|c|c|c|c|c|c|c|}
\hline \multirow[t]{2}{*}{ FACTORS } & \multicolumn{2}{|c|}{$\frac{\text { COMMUNITY }}{\text { COLLEGES }}$} & \multicolumn{2}{|c|}{$\frac{\text { FOUR-YEAR }}{\text { COLLEGE }}$} & \multicolumn{2}{|c|}{ ALI COLIEGES } \\
\hline & 8 & $(n)$ & 8 & (n) & 8 & (n) \\
\hline $\begin{array}{l}\text { PERSONALLY KNEW A } \\
\text { NURSE }\end{array}$ & 49 & $(37)$ & 63 & (43) & 56 & $(80)$ \\
\hline $\begin{array}{l}\text { FAMILY MEMBER IS A } \\
\text { NURSE }\end{array}$ & 28 & $(21)$ & 38 & $(26)$ & 33 & $(47)$ \\
\hline $\begin{array}{l}\text { TOOK CARE OF } \\
\text { SERIOUSLY ILI PERSON } \\
\end{array}$ & 36 & $(27)$ & 16 & (11) & 27 & (38) \\
\hline $\begin{array}{l}\text { LIVED WITH SERIOUSLY } \\
\text { ILL PERSON }\end{array}$ & 17 & (13) & 9 & (6) & 13 & (19) \\
\hline $\begin{array}{l}\text { DEATH OF SOMEONE } \\
\text { CLOSE TO ME }\end{array}$ & 29 & $(22)$ & 12 & (8) & 21 & $(30)$ \\
\hline
\end{tabular}

that they were moderately to very strongly influenced by the desire to "start a career in medical administration." Results of the comparison of previous studies are ambiguous as to whether male nursing students are more likely than female nursing students to express a desire to become involved in medical administration. A 1970 study by Auster and Auster found that male nursing students were interested in working in nursing administration (Auster and Auster 1970, pp. 66-70). William's study, however, found that male baccalaureate students preferred areas of nursing which usually require a great deal of patient contact, areas unlike administration (Williams 1973, p. 523). Among the students surveyed for this study, the males were much 
more likely to be motivated by an interest in administration. As illustrated in Table VIII, thirty-eight percent of the male respondents indicated that an interest in medical administration was a moderate to very strong influence on their decision to study nursing, compared to fifteen percent of the female respondents who indicated the same.

As shown in Table IX few significant differences exist between the community college students and the

TABLE VIII

IMPORTANCE OF SOCIAL AND SOCIO-ECONOMIC FACTORS IN THE DECISION TO STUDY NURSING

$\mathrm{N}=143$

\begin{tabular}{|c|c|c|c|c|c|}
\hline FACTORS & $\begin{array}{l}\text { VERY } \\
8 \quad(n) \\
\end{array}$ & $\begin{array}{l}\text { MODERATE } \\
8(n) \\
\end{array}$ & $\begin{array}{l}\text { SOMEWHAT } \\
8(\mathrm{n}) \\
\end{array}$ & $\begin{array}{r}\text { NOT VERY } \\
8 \quad(n) \\
\end{array}$ & $\begin{array}{l}\text { NOT / ALI } \\
\% \quad(n) \\
\end{array}$ \\
\hline $\begin{array}{l}\text { A SENSE OF A } \\
\text { "CALLING" TO } \\
\text { SERVE OTHERS }\end{array}$ & $39(56)$ & $27(38)$ & $12(17)$ & 12 (17) & 8 (11) \\
\hline $\begin{array}{l}\text { TO BEGIN A } \\
\text { CAREER IN } \\
\text { MEDICAL CARE } \\
\end{array}$ & 44 (63) & $23(33)$ & $22(32)$ & (8) & (4) \\
\hline $\begin{array}{l}\text { TO IMPROVE } \\
\text { EARNINGS OR } \\
\text { SOCIAI STANDING }\end{array}$ & $21(30)$ & $32(45)$ & $22(32)$ & $16(22)$ & $10(14)$ \\
\hline $\begin{array}{l}\text { TO START A } \\
\text { CAREER IN } \\
\text { MEDICAL } \\
\text { ADMINISTRATION }\end{array}$ & $7(10)$ & $13(18)$ & $15(22)$ & $21(30)$ & 41 (59) \\
\hline MALES $\quad(N=26)$ & $15 \quad(4)$ & $23(6)$ & $12(3)$ & $12(3)$ & $38(10)$ \\
\hline FEMALES $(N=115)$ & $5 \quad(6)$ & $10(11)$ & $17(19)$ & $23(26)$ & $41(47)$ \\
\hline $\begin{array}{l}\text { IT WILL PROVIDE } \\
\text { A CHANCE TO HELP } \\
\text { OTHERS }\end{array}$ & $65(93)$ & $25(36)$ & (8) & (2) & (2) \\
\hline
\end{tabular}

Percentages in each category do not necessarily add to 100 due to missing responses and rounding. 
baccalaureate students concerning the influence of these social and socio-economic factors. Nonetheless, it is curious that twenty-three percent of the community college students were moderately to very strongly influenced by an interest in medical administration, while only sixteen percent of the baccalaureate students were. This was unanticipated, as baccalaureate students were expected to be more interested in professional aspects of nursing such as administration. One explanation is that the community

TABLE IX

IMPORTANCE OF SOCIAL AND SOCIO-ECONOMIC FACTORS IN THE DECISION TO STUDY NURSING, CONTRASTED BY TYPE OF COLLEGE $\mathrm{N}=75$ FOR COMMUNITY COLLEGES, N=68 FOR FOUR-YEAR COLLEGE, AND COMBINED $\mathrm{N}=143$

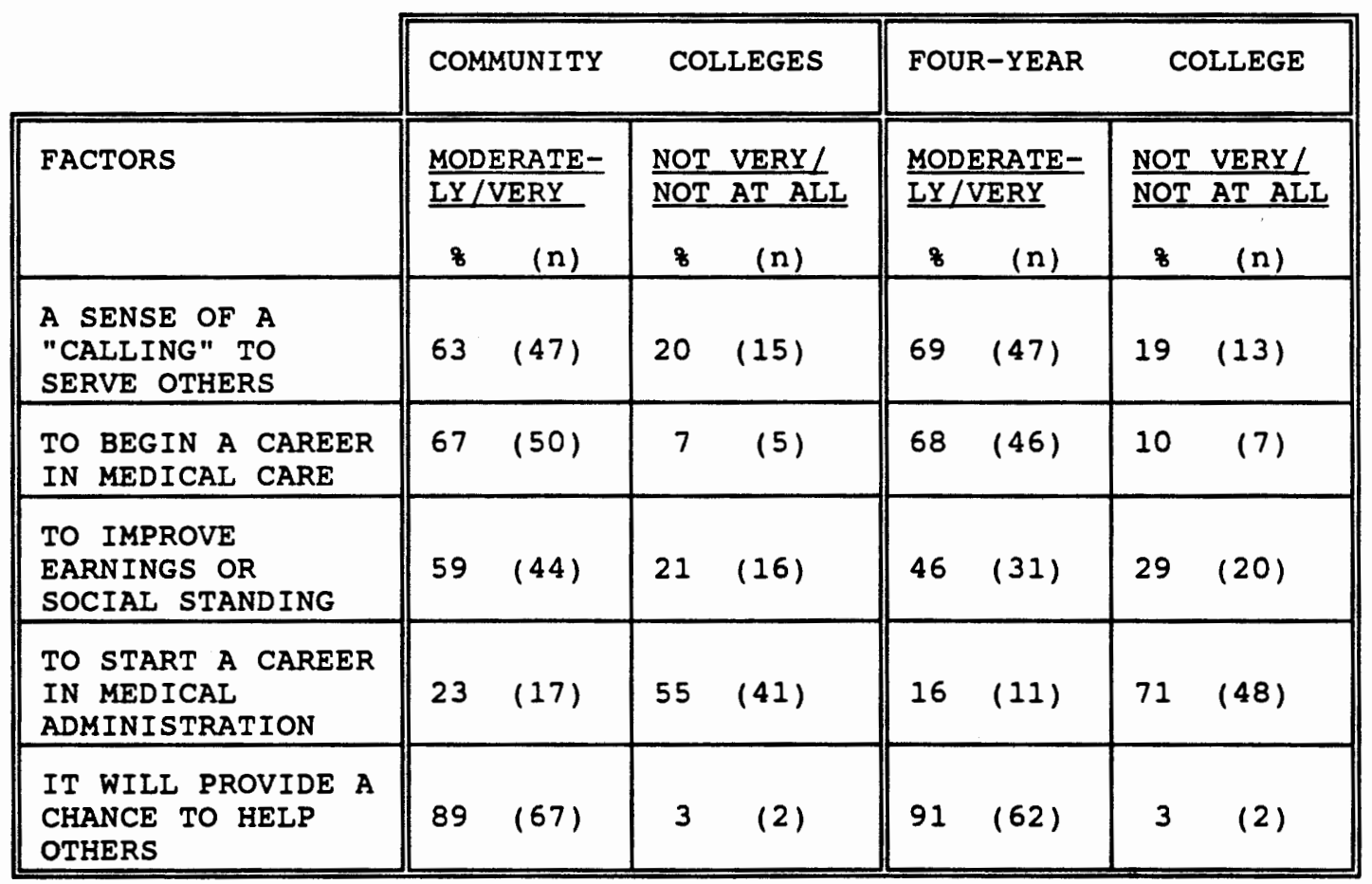

Percentages do not necessarily add to 100 due to rounding, missing responses, and the omission of the category "somewhat." 
college students had more experience in health care (see Table I) and therefore were more likely to be exposed to and aware of administrative positions in nursing. Additionally, the community college students were an average of five years older than the baccalaureate students (see Table I) which may be associated with their greater interest in administration.

\section{CONCEPTIONS OF ROLE}

The data illustrate that the students conceive of nursing as a helping and caring occupation. students were asked to indicate how important eleven activities would be to them in their future roles as nurses. These activities included performing medical procedures, talking to and comforting patients, administrative work, meetings, and completing patient charts. Presented in Table $\mathrm{X}$ are the responses concerning these activities. Talking to and comforting patients was clearly the most important activity with eighty percent of the students indicating that this would be very important to them as a nurse. Also important was performing medical procedures which was rated as very important by fifty-four percent of the respondents. These data are telling because they demonstrate that the "helping" and "comforting" component of nursing is more important to students than the procedural component. of all eleven activities referred to above, the least 
significant was meetings. Only six percent of the students indicated that meetings would be very important to them. Meetings were less important than contributing to professional journals, which was very important to fifteen percent of the respondents and at least moderately important to thirty-seven percent (categories "very" and "moderately" in Table $\mathrm{X}$ were combined). Meetings may have been assigned low priority in part because they were not defined in the questionnaire. Students may have experienced some confusion about whether meetings referred to shift change meetings, staff meetings, or professional meetings. Predictably, re-stocking supplies, cleaning, and making beds were very important to only seven percent of the students.

The students surveyed in this study believed the role of a nurse to be a caring one, the same finding reported by Davis, olesen, Whittaker, and other researchers (Kersten, Bakewell, and Meyer 1991). Additionally, they viewed contributing to professional journals as more important than administrative work, meetings, and re-stocking supplies, cleaning, and making beds. This indicates that contemporary student nurses have incorporated aspects of professional ideology into their conceptions of the nursing role. At the same time they seem to have only weakly embraced the administrative or management components of nursing. 
TABLE $\mathrm{X}$

IMPORTANCE OF FACTORS TO STUDENTS IN THEIR FUTURE ROLES AS NURSES

$\mathrm{N}=143$

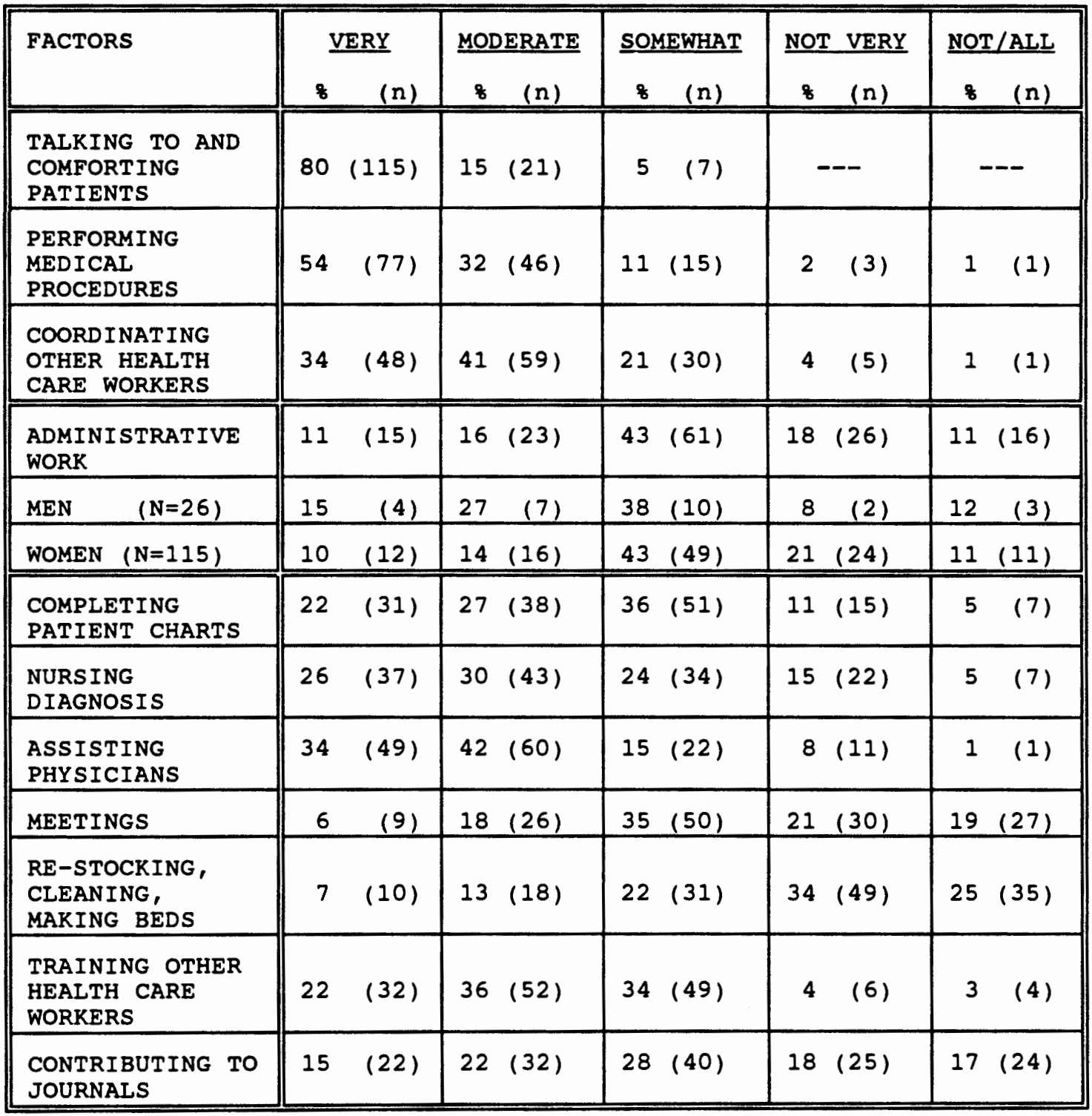

Percentages do not necessarily add to 100 due to rounding and missing responses. 
Administrative nursing is clearly more important to the male students than the female students. The data in Table $\mathrm{x}$ indicate that forty-two percent of the men responded that administrative work would be moderately to very important to them as a nurse while only twenty-four percent of the women did so (categories "very" and "moderately" in Table $\mathrm{X}$ were combined).

There was little difference between the community college students and the baccalaureate students in terms of the importance of administrative work, meetings or performing medical procedures (see Table XI). As expected, however, the baccalaureate students placed more importance on the professional component (contributing to professional journals). Forty-six percent indicated that this would be moderately to very important to them as a nurse, while thirty-one percent of the community college students indicated the same. Interestingly, slightly more of the baccalaureate students placed greater emphasis on the "comfort" and "helping" component of a nurse's role. Ninety-nine percent of the baccalaureate students indicated that talking to and comforting patients would be moderately to very important to them as nurses while ninety-two percent of the community college nurses did so.

students were asked to indicate the importance to being a good nurse of a number of traits and characteristics. These data are presented in Table XII. 
TABLE XI

IMPORTANCE OF FACTORS TO STUDENTS IN THEIR FUTURE ROLES

AS NURSES, CONTRASTED BY TYPE OF COLLEGE

$\mathrm{N}=75$ FOR COMMUNITY COLLEGES AND

$\mathrm{N}=68$ FOR FOUR YEAR COLLEGE

\begin{tabular}{|c|c|c|c|c|}
\hline & COMMUNITY & COLLEGES & FOUR-YEAR & COLLEGES \\
\hline FACTORS & $\begin{array}{l}\text { MODERATE- } \\
\text { LY/VERY } \\
8 \quad(\mathrm{n}) \\
\end{array}$ & 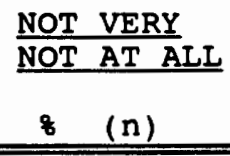 & $\begin{array}{l}\text { MODERATE- } \\
\text { LY/VERY } \\
\& \quad(\mathrm{n}) \\
\end{array}$ & 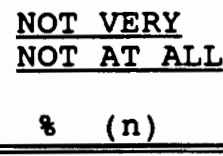 \\
\hline $\begin{array}{l}\text { TALKING TO/ } \\
\text { COMFORTING } \\
\text { PATIENTS } \\
\end{array}$ & $92 \quad(69)$ & $0 \quad(0)$ & 99 (67) & $0 \quad(0)$ \\
\hline $\begin{array}{l}\text { PERFORMING } \\
\text { MEDICAL } \\
\text { PROCEDURES }\end{array}$ & $89 \quad(67)$ & 1 (1) & $82(56)$ & $4 \quad(3)$ \\
\hline $\begin{array}{l}\text { COORDINATING } \\
\text { PATIENT CARE }\end{array}$ & $67 \quad(50)$ & $5 \quad(4)$ & $84(57)$ & 2 (1) \\
\hline $\begin{array}{l}\text { ADMINISTRA- } \\
\text { TIVE WORK }\end{array}$ & $27 \quad(20)$ & $33(25)$ & 27 (18) & $25(17)$ \\
\hline $\begin{array}{l}\text { PATIENT } \\
\text { CHARTS }\end{array}$ & $45 \quad(34)$ & 15 (11) & $52(35)$ & 16 (11) \\
\hline $\begin{array}{l}\text { NURSING } \\
\text { DIAGNOSIS }\end{array}$ & $60 \quad(45)$ & $20(15)$ & $52(35)$ & 21 (14) \\
\hline $\begin{array}{l}\text { ASSISTING } \\
\text { PHYSICIANS } \\
\end{array}$ & $79 \quad(59)$ & 8 (6) & $74(50)$ & 9 (6) \\
\hline MEETINGS & $28 \quad(21)$ & $44 \quad(33)$ & $21(14)$ & $35 \quad(24)$ \\
\hline $\begin{array}{l}\text { RE-STOCKING, } \\
\text { CLEANING, } \\
\text { MAKING BEDS }\end{array}$ & $25 \quad(19)$ & $57(43)$ & $13(9)$ & $60(41)$ \\
\hline $\begin{array}{l}\text { TRAINING } \\
\text { OTHER HEALTH } \\
\text { CARE WORKERS }\end{array}$ & $63 \quad(47)$ & $7 \quad(5)$ & $54(37)$ & $7 \quad(5)$ \\
\hline $\begin{array}{l}\text { CONTRIBUTING } \\
\text { TO JOURNALS }\end{array}$ & $31 \quad(23)$ & 47 (35) & 46 (31) & $21(14)$ \\
\hline
\end{tabular}

Percentages do not necessarily add to 100 due to rounding, missing responses, and omission of the category "somewhat". 
Ninety-two percent of the respondents indicated that good decision making and problem solving abilities were very important. Eighty-seven percent indicated that good communication skills were also very important to being a good nurse. These two characteristics were both deemed more important than intellectual curiosity, ability to follow directions efficiently, good technical skills,

TABLE XII

IMPORTANCE OF CHARACTERISTICS TO BEING A GOOD NURSE

$\mathrm{N}=143$

\begin{tabular}{|c|c|c|c|c|c|}
\hline CHARACTERISTIC & $\begin{array}{l}\text { VERY } \\
8 \quad(n)\end{array}$ & $\begin{array}{c}\text { MODERATE } \\
8(\mathrm{n}) \\
\end{array}$ & $\begin{array}{l}\text { SOMEWHAT } \\
\& \quad(n)\end{array}$ & $\begin{array}{l}\text { NOT VERY } \\
8 \quad(n)\end{array}$ & $\begin{array}{l}\text { NOT/ALL } \\
8 \text { (n) }\end{array}$ \\
\hline $\begin{array}{l}\text { INTELLECTUAL } \\
\text { CURIOSITY }\end{array}$ & $66 \quad(95)$ & $29(41)$ & $4 \quad(6)$ & -- & -- \\
\hline $\begin{array}{l}\text { GOOD DECISION } \\
\text { MAKING AND } \\
\text { PROBLEM SOLV- } \\
\text { ING ABILITY }\end{array}$ & 92 (131) & $7 \quad(10)$ & 1 (1) & -- & -- \\
\hline $\begin{array}{l}\text { ABILITY TO } \\
\text { FOLLOW } \\
\text { DIRECTIONS } \\
\text { EFFICIENTLY }\end{array}$ & $69 \quad(98)$ & $25(36)$ & $6 \quad(8)$ & -- & -- \\
\hline $\begin{array}{l}\text { GOOD } \\
\text { COMMUNICATION } \\
\text { SKILLS }\end{array}$ & $87(125)$ & 11 (15) & 1 (1) & 1 (1) & -- \\
\hline $\begin{array}{l}\text { GOOD TECHNICAL } \\
\text { SKILLS }\end{array}$ & 76 (109) & $20(29)$ & 3 (4) & --- & -- \\
\hline $\begin{array}{l}\text { ABILITY TO } \\
\text { TOLERATE } \\
\text { STRESS } \\
\end{array}$ & $71(102)$ & $22(32)$ & $6 \quad(8)$ & -- & -- \\
\hline $\begin{array}{l}\text { CARING OR } \\
\text { EMPATHETIC } \\
\text { PERSONALITY }\end{array}$ & 79 (113) & $16(23)$ & $4 \quad(6)$ & --- & -- \\
\hline
\end{tabular}

Percentages do not necessarily add to 100 due to rounding and missing responses. 
ability to tolerate stress, and possessing a caring or empathetic personality. Intellectual curiosity was the least important of all of these items with sixty-six percent of the respondents indicating that intellectual curiosity was very important to being a good nurse. While this is still a majority of the students, it is the least important of all the aforementioned characteristics or traits. This could indicate a lack of identification with a professional role as intellectual curiosity is usually a characteristic associated with professionals.

Demonstrated in Table XIII are differences in how important the various personality traits were to the community college students compared to the baccalaureate students. Seventy-two percent of the four-year students indicated that intellectual curiosity was very important to being a good nurse while only sixty-two percent of the community college students did so (the categories "somewhat," "not very," and "not at all" were combined in Table XIII to show variance). Ninety-four percent of the four-year students compared to eighty-one percent of the community college students indicated that good communication skills were very important to being a good nurse. Seventy-nine percent of the four-year students versus sixty-four percent of the community college students indicated that the ability to tolerate stress was very important. Finally, eighty-eight percent of the four-year 
TABLE XIII

IMPORTANCE OF CHARACTERISTICS TO BEING A

GOOD NURSE, CONTRASTED BY TYPE OF COLLEGE

$\mathrm{N}=75$ FOR COMMUNITY COLLEGES AND $\mathrm{N}=68$ FOR FOUR-YEAR COLLEGE

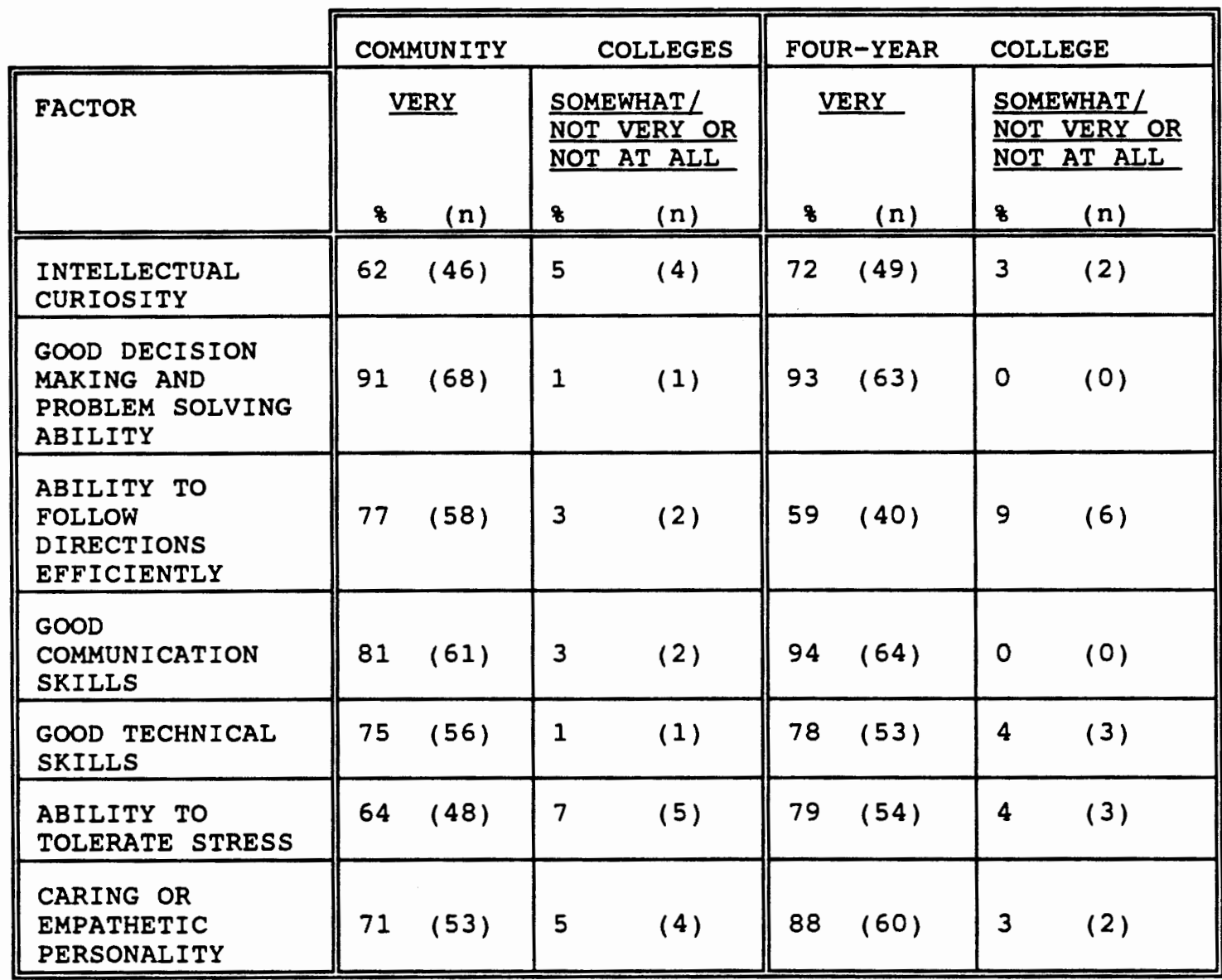

Percentages do not necessarily add to 100 due to rounding, missing responses, and the omission of the category "somewhat".

students compared to seventy-one percent of the community college students indicated that a caring or empathetic personality was very important.

The four year students found intellectual curiosity, good communication skills, the ability to tolerate stress, and a caring or empathetic personality to be more important 
to being a good nurse than did the community college students. The only personal characteristic which the community college students found to be more important than the four-year students was the ability to follow directions efficiently, which was deemed very important by seventyseven percent of the community college students compared to fifty-nine percent of the four-year students. The baccalaureate students placed more emphasis on intellectual curiosity, which is a trait associated with a professional role, than did community college students. At the same time, the community college students placed more emphasis on the ability to follow directions efficiently which is a trait not generally associated with a professional role. The baccalaureate students appear to see the role of a nurse as more professional than do community college students.

The student nurses surveyed for this study conceive of the role of a nurse as a caring one. A nurse provides support and comfort to patients along with required medical procedures. The students likely do not see themselves as administrators, leaders, or educators. Some uncertainty exists concerning whether or not the students conceive of themselves as traditional professionals. They indicate that contributing to professional journals is somewhat important to them but at the same time do not strongly embrace management or administration. 
EXPECTATIONS, IDEALS, AND REALITY

One purpose of this research was to compare how the student nurses' expectations of the nursing role compare with the reality of being a nurse. Additionally, the questionnaire was designed to measure differences between how the students conceived of ideal nursing and what they believed the reality of nursing to be.

\section{Expectations and Reality}

In order to compare expectations and reality, it is necessary to summarize literature examining the activities and roles in which contemporary nurses are involved. Some difficulty is involved in gaining an accurate understanding of what most nurses do on a day-to-day basis. An attempt to do this, however, was made by relying on a literature review, primarily reports of surveys and studies completed in the last ten to twenty years.

Nine studies in the mid to late $1980^{\prime}$ s outline the general activities in which nurses are involved. The nurses studied worked in many different hospitals throughout the United States. An average of data from these nine studies showed nurses spending thirty-four percent of their time on direct patient care. Fifty-two percent of the nurses' time was spent on indirect patient care or unit management. Finally, fourteen percent of the nurses' time was spent on personal activities (Feyerherm 
1966; Saren and Straub 1970; Moses and Roth 1979; Minyard, Wall, and Turner 1986; Lake 1987; Misener, Frelin, and Twist 1987; Rantz and Hauer 1987; Patient Intensity for Nursing Index 1988; and Williamson and Johnston 1988). These data can only be used in a general exploratory sense, because although most of the researchers used definitions of activities which were consistent, there were some differences. For example, most of the studies included time spent transporting patients in the direct care category, but one did not. Additionally, these studies are not directly comparable to this study because of slight differences in definitions and because, while some of the studies included only registered nurses, others included all nursing personnel. In general the following categories of activities were identified:

1. Direct Care: All nursing activities performed in the presence of the patient and/or family. Examples include administering medications, assessing patient needs, all treatments and procedures, and all aspects of basic physical care.

2. Indirect Care: All nursing activities done away from the patient but on a specific patient's behalf. Examples include charting, seeking consultation, writing nursing care plans and preparing medications.

3. Unit Related: These were activities related to general maintenance of the nursing unit such as clerical work, cleaning, ordering supplies, checking equipment, attending meetings, running errands, classifying patients, attending rounds, preparing reports, and supervising staff and students.

4. Personal: Activities related to meals, breaks, personal phone calls, and socializing with coworkers. 
A 1979 study by Moses and Roth utilized data from the 1977 National Sample Survey of Registered Nurses. They found that fifty-seven percent of all employed registered nurses spent the majority of their time in direct patient care activities. Seventy-nine percent of the nurses had positions in which direct patient care was the single most important function. of the nurses who spent most of their time in direct care, eighty-four percent routinely administered medications, sixty-seven percent sustained and supported patients during diagnosis or therapy, sixty-six percent instructed patients in illness management, sixtytwo percent assisted the physician during examination, fifty-nine percent obtained health histories, and fiftythree percent implemented therapy (Moses and Roth 1979, pp. $1745,1753)$

A 1987 study by Misener, Frelin, and Twist involved nine study sites in critical care units, medical/surgical units, psychiatric units, obstetric units, newborn units, and pediatric units. They monitored nursing personnel for a time period equivalent to a total of 461 eight-hour shifts, for a total of 17,817 hours of nursing time. This study involved licensed practical nurses and aides, as well as registered nurses.

The most predominant activity was direct care which consumed twenty-five percent of the nursing personnel's time. The next most prevalent activity was charting and 
clerical work which occupied eleven percent of their time. Travel and transportation also used up eleven percent of the workers' time. Communicating consumed ten percent of available time, while workers spent nine percent of their time waiting to administer care. Five percent involved medical supplies and equipment, and finally four percent was consumed by conferences (Misener, Frelin, and Twist 1987, p. 36). These percentages are not directly comparable to the research for this thesis as Misener, Frelin, and Twist studied licensed practical nurses and aides as well as registered nurses. The data would likely differ significantly if only registered nurses had been included.

A 1987 study by Rantz and Hauer focused on all nursing personnel in an acute care facility. These researchers, however, separated the data so that registered nurses could be specifically identified. They made 2,814 thirty minute observations of eighty-six registered nurses during all shifts. Rantz and Hauer reported that thirty-five percent of the registered nurses' time was spent on direct care activities. Fifty-five percent was consumed by non-direct care activities. Non-productive time which involved activities such as breaks, waiting, personal phone calls, and socializing, consumed eleven percent of the nurses' time (Rantz and Hauer 1987, p. 40).

A similar study was completed by Minyard, Wall, and 
Turner in 1986. Activities were observed in fifteen general medical-surgical, specialty, and critical care units at a 700-bed hospital. Ten shifts (including day, evening, and night shifts) in each unit were studied. over 175,000 samples of nursing activity were drawn. They found that hospital nursing personnel spent thirty-three percent of their time in direct care, twenty percent in unitrelated activities, and twenty percent non-productively. Minyard, Wall, and Turner measured non-productive time separately for registered nurses and found that it consumed eleven percent of their time. This corresponds with the eleven percent spent non-productively by registered nurses in the Rantz and Hauer study. The eleven percent nonproductive time in both studies shows an element of consistency. This is important in estimating the activities of an average nurse.

The previous studies were used as a rough reference point for assessing whether or not the students surveyed for this study have expectations which coincide with the realities of nursing. Some problems of uniformity and definition have been mentioned. Additionally, while all of the aforementioned studies focused on hospitals, there are many nurses employed elsewhere about whom comprehensive information is lacking. This lack precludes the inclusion of any such data in this report. All of these conditions make any assessment of the correspondence between student 
expectations and reality an estimate.

No striking disagreement between the students' expectations of nursing and the realities of nursing are apparent. There are, however, some slight discrepancies. only thirty-six percent of the students believed that the average nurse engages in administrative work often or always (see Table XIV). While this may seem like a sizeable percentage, all the other nursing activities listed in Table XIV were considered more prevalent except contributing to professional journals. Activities such as attending meetings, re-stocking supplies, cleaning, and making beds were considered more common activities by the students than was administrative work. The Misener, Frelin, and Twist study, which appears to be consistent with the others, shows that nursing personnel spent nine percent of their time in administrative duties. While this may not seem a considerable amount of time it is comparable to the time spent on clerical and charting activities or the time spent communicating (Misener, Frelin, and Twist 1987, p. 236). Additionally, the nine percent applied also to licensed practical nurses and nurse's aides whose roles would be expected to include fewer administrative activities than would the role of registered nurse. Contemporary nursing appears to involve considerable administrative activity, which may be underestimated by the students. 
TABLE XIV

FUTURE IMPORTANCE OF VARIOUS TASKS TO THE STUDENTS AS NURSES AND STUDENTS' BELIEFS CONCERNING HOW OFTEN THE AVERAGE NURSE ENGAGES IN THESE TASKS

$\mathrm{N}=143$

\begin{tabular}{|c|c|c|c|c|}
\hline \multirow{2}{*}{$\begin{array}{l}\text { NURSING ACTIVITY } \\
\text { TALKING TO AND } \\
\text { COMFORTING PATIENTS }\end{array}$} & \multicolumn{2}{|c|}{ 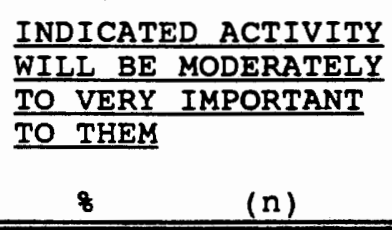 } & \multicolumn{2}{|c|}{$\begin{array}{l}\text { BELIEVED THE } \\
\text { AVERAGE NURSE } \\
\text { ENGAGES IN ACTIVITY } \\
\begin{array}{ll}\text { OFTEN OR ALWAYS } \\
\& & (\mathrm{n})\end{array}\end{array}$} \\
\hline & 95 & $(136)$ & 76 & $(108)$ \\
\hline $\begin{array}{l}\text { PERFORMING MEDICAL } \\
\text { PROCEDURES }\end{array}$ & 86 & (123) & 82 & $(117)$ \\
\hline $\begin{array}{l}\text { COORDINATING OTHER } \\
\text { HEALTH CARE WORKERS }\end{array}$ & 75 & $(107)$ & 51 & (73) \\
\hline ADMINISTRATIVE WORK & 27 & $(38)$ & 36 & (51) \\
\hline PATIENT CHARTS & 48 & $(69)$ & 93 & (133) \\
\hline NURSING DIAGNOSIS & 56 & $(80)$ & 62 & $(88)$ \\
\hline MEETINGS & 25 & (35) & 53 & $(76)$ \\
\hline $\begin{array}{l}\text { RE-STOCKING, } \\
\text { CLEANING, MAKING BEDS }\end{array}$ & 20 & (28) & 56 & $(80)$ \\
\hline $\begin{array}{l}\text { CONTRIBUTING TO } \\
\text { JOURNALS }\end{array}$ & 38 & (54) & 8 & (11) \\
\hline
\end{tabular}

All 143 students were asked if the activities will be moderately or very important to them as a nurse and all 143 students were asked if they believe the average nurse engages in the activities often or always. Row n's represent responses, not respondents.

Fifty-six percent of the students indicated that the average nurse engages in re-stocking supplies, cleaning, and making beds often or always (see Table XIV). Research indicates, however, that registered nurses may not spend very much time in these activities. The aforementioned study of all nursing personnel shows only five percent of their time was spent working on medical supplies or 
equipment. Again, it is expected that registered nurses would spend even less time on such activities than licensed practical nurses or nurse's aides. It may be that with the increase of aides and technicians in hospitals in the late 1980's and early 1990's, registered nurses are doing less of these cleaning and menial tasks. Student nurses may not be fully aware of the activities of contemporary nurses. In general, it seems that these first-year students have a very reasonable grasp of what nurses do. As previously noted, fifty-four percent of the students have had prior experience in health care fields (see Table I). Additionally, the students were surveyed near the completion of their first year of nursing school, meaning they have likely already had exposure to clinical nursing, even if they have never worked in health care. These factors combine to give the students a good understanding of what is involved in nursing.

\section{Expectations and Ideals}

One group of questions on the questionnaire asked the students to indicate how important each of eleven tasks would be to them in their role as a nurse. Another group of questions asked the students to indicate how often they believed the average nurse engages in each of ten activities. Most of the items in these two groups of questions are similar allowing comparison between what the students desire from nursing and what they actually expect. 
As previously indicated, the students in this study placed considerable importance on talking to and comforting patients. Ninety-five percent of the respondents indicated that talking to and comforting patients would be very important to them in their future role as a nurse. Seventy-six percent of the respondents indicated they believed that the average nurse engages in talking to and comforting patients often or always (see Table XIV). These data show that the students believe talking to and comforting patients to be a widespread component of nursing, corresponding to their ascribing importance to it. The students felt that the average nurse is significantly involved in performing medical procedures, coordinating patient care, completing patient charts, and performing nursing diagnosis. For the most part these activities were also important to the student nurses. For many of the items, there was agreement between what was important to the students and what they felt the average nurse does.

There were a few differences, however, between what the students felt would be important to them as nurses and what they believed nurses actually did. One discrepancy concerns meetings. Only twenty-five percent of the respondents indicated that meetings would be moderately to very important to them in their role as a nurse. Fiftythree percent indicated, however, that the average nurse is 
involved with meetings often or always (see Table XIV). The students believe that meetings are a significant component of the nursing role, but do not place very much importance on them. (Because "meeting" was not defined in the survey, it is not known what type of meetings the students conceived of. For example, it may be that they placed importance on professional meetings but thought the survey question pertained to staff meetings.)

An additional discrepancy exists between the importance the students placed on charting and the prevalence of charting in nursing. A full ninety-three percent of the students indicated that they believed the average nurse works on patient charts often or always. This indicates that the students are aware of the ubiquitous chart in nursing. Only forty-eight percent of the students, however, indicated that completing patient charts would be moderately to very important to them. Apparently, they are aware of the prevalence of charting, but do not find it to be very important to the role of a nurse.

As expected there is disagreement between the importance placed on menial tasks and how often the students believe nurses engage in these tasks. Only twenty percent of the students indicated that re-stocking supplies, cleaning and making beds would be moderately to very important to them as a nurse. Fifty-six percent believed, however, that the average nurse engages in these 
activities often or always.

It appears that the students believe meetings, charting, and menial tasks play too large a role in nursing. This is not surprising in that the students make it clear that patient care activities are very important to them. This indicates that they would prefer nursing to involve more direct and less non-direct care.

one disagreement between what was important to the students and what they believed nurses actually did involved a professional aspect of nursing, contributing to professional journals. Thirty-eight percent of the students indicated that contributing to professional journals would be moderately to very important to them in their future roles as nurses. Only eight percent of the students believed, however, that the average nurse engages in journal writing often or always (see Table XIV). It appears that the students find this professional component of nursing important, but seem to accept that it is not a prevalent component of the activities of most nurses.

The community college students and four-year students differ concerning what is important to them and what they believe nurses actually do. The activities for which differences are apparent are meetings, re-stocking, cleaning and making beds, and contributing to professional journals. As shown in Table XV, twenty-eight percent of the community college students responded that meetings will 
TABLE XV

FUTURE IMPORTANCE OF VARIOUS TASKS TO THE STUDENTS AS NURSES AND STUDENTS' BELIEFS CONCERNING HOW OFTEN

THE AVERAGE NURSE ENGAGES IN THESE TASKS, CONTRASTED BY TYPE OF COLLEGE

$\mathrm{N}=75$ FOR COMMUNITY COLLEGES AND $\mathrm{N}=68$ FOR FOUR-YEAR COLLEGE

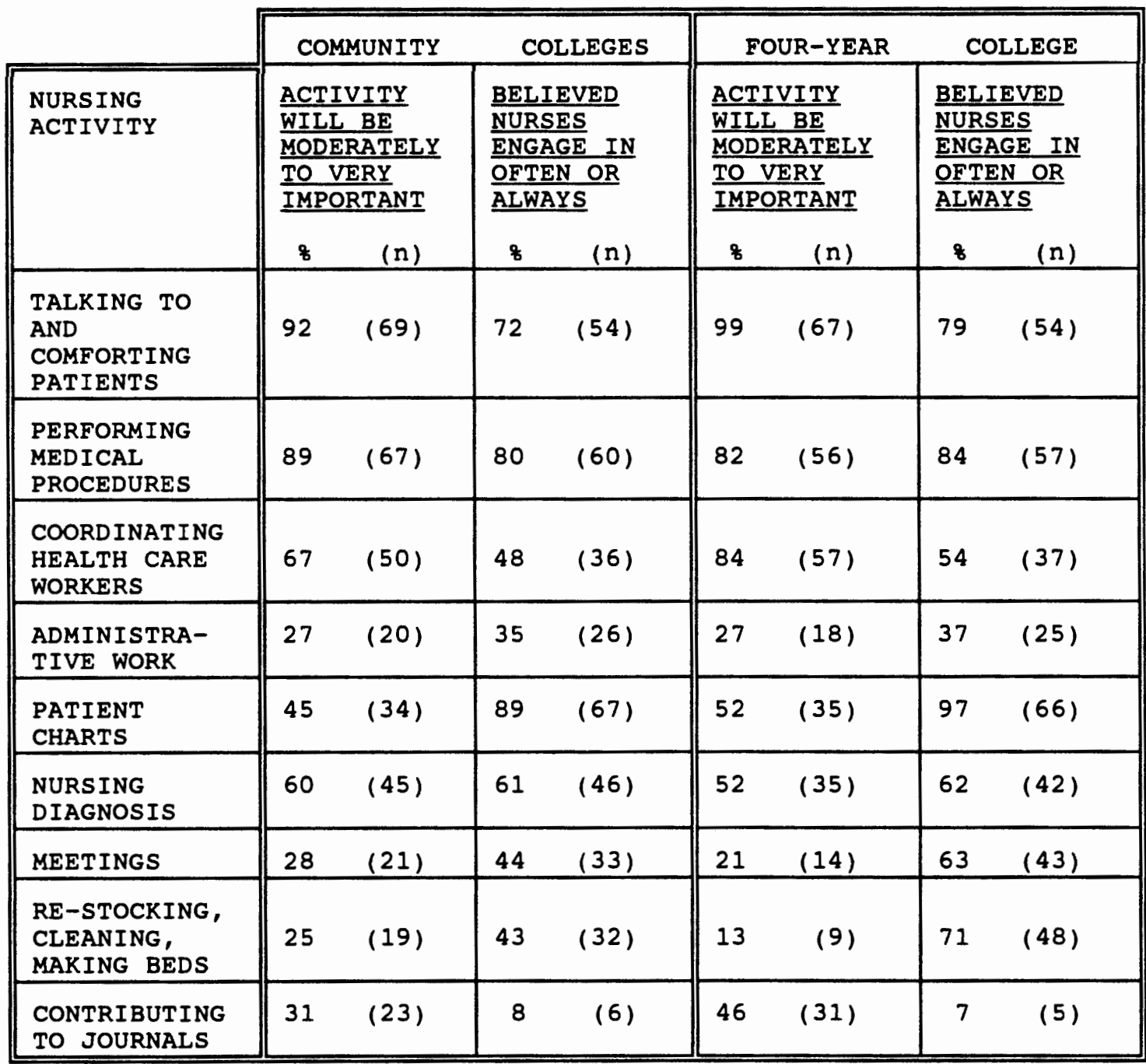

be moderately to very important to them as a nurse and forty-four percent believed that the average nurse engages in meetings often or always. Twenty-one percent of the four-year students indicated that meetings will be 
moderately to very important to them, but a full sixtythree percent believed the average nurse attends meetings often or always. Concerning meetings, there is much greater disagreement between students' ideals and expectations of reality for the baccalaureate students than for the community college students.

Twenty-five percent of the community college students indicated that re-stocking, cleaning, and making beds will be moderately to very important to them and forty-three percent responded that the average nurse engages in these activities often or always. Thirteen percent of the baccalaureate students indicated that re-stocking, cleaning, and making beds will be moderately to very important to them. A full seventy-one percent, however, indicated that the average nurse engages in these activities often or always. For the baccalaureate students this represents a considerable difference between what is important to them and what they believe the average nurse does.

Thirty-one percent of the community college nurses indicated that contributing to professional journals would be moderately to very important to them as a nurse while eight percent believed the average nurse does this often or always. This is a considerable difference, but not as great as for the baccalaureate students of whom forty-six percent indicated that contributing to professional 
journals will be moderately to very important to them and of whom only seven percent responded that the average nurse engages in journal writing often or always. Perhaps the baccalaureate students believe journal writing should be a more significant component of nursing or perhaps they do not see themselves as average nurses. 
CHAPTER V

\section{SUMMARY AND CONCLUSION \\ SUMMARY OF DEMOGRAPHICS}

The demographic background of the students surveyed for this study is considerably different from that of college students in general. First, a considerable majority of the students are female, although the proportion of males is now significant. Their mean age was thirty-two years, significantly older than contemporary college students in general (Nursing Datasource 1992, p. 19). The students were predominately Caucasian with a significant number being Asian or Pacific Islander. The majority of the students were either married or divorced, and approximately half had children. About a third had baccalaureate degrees and over half had previous experience in health care.

These data indicate that the student nurses surveyed for this study were not "typical college students." Many were likely returning students who were changing careers. If these data are at all nationally representative, the demographic background of aspiring nurses has significantly changed since the 1960's. 
SUMMARY OF MOTIVATIONS

The most important motivation for entering a nursing program involved a desire to help others. A full seventynine percent of the students in both baccalaureate and associate degree programs indicated that the desire to help people was very important in influencing their decision to enter nursing school. The desire to do important work and the opportunity to work with a variety of people were also very strong motivating factors. Additionally, the students indicated that they were motivated to pursue nursing because it is exciting and is respected. All of these elements were more of a motivating factor than practical concerns such as a good salary and job security.

It seems that student nurses have idealistic motivations for entering nursing programs. They may rank items such as job security, good salary, and good hours low for several reasons. First, these factors may not be important to them and second, they may feel that nursing does not offer these things.

The students clearly did not enroll in nursing programs for "life insurance" should getting married and having a family not occur. In fact, given that more students indicated that they were married than single, this is obviously not the reason for studying nursing. Only six percent of the students were moderately to very strongly 
influenced to pursue nursing by the desire to meet a "lifepartner." Additionally, several of the students may have been offended by this question as they crossed it out on the questionnaire.

Eighty-nine percent of the students indicated that they intended to make nursing a life-long career and planned to work full-time. It appears that being a nurse will be a primary status for these students, not a rather temporary one as it was for the students in the Davis, Olesen, and Whittaker study (Davis 1972, p. 45).

of the categories of people listed on the questionnaire, students' families were the single most important influence on their decisions to enter nursing programs. Fifty-three percent of the students indicated that family was moderately to very important in their decision to study nursing. The next most important category was friends. Both teachers and co-workers were more important than guidance counselors. As one would expect, with the average age of the students at thirty-two years, they were not significantly motivated by guidance counselors.

A sense of a calling to serve others is still important to student nurses, with sixty-six percent of the students indicating that this was a moderate to very important factor in their decision to study nursing. As previously discussed, nursing was traditionally viewed as a 
calling (Davis 1966, p. 69; Elzinga 1990, p. 155) and it is interesting to note that even with increased professionalization and other changes, students still see nursing this way.

The information culled from the survey is somewhat ambiguous concerning professional motivations. It seems apparent that the students see nursing as a profession, however, not necessarily a profession as defined in the introduction to this thesis. Overall, the students placed little importance on the desire to start a career in medical administration as a motivation for entering nursing programs. The question of whether student nurses see nursing as a traditional profession will be further explored in the next section.

\section{SUMMARY OF CONCEPTIONS OF ROLE}

The survey data clearly indicate that the students saw the role of a nurse as a caring one. They believed talking to, comforting patients, and possessing a caring or empathetic personality to be important for nurses. Additionally, while the students see the technical aspect of nursing as important, it is secondary to the caring role. They generally do not see nurses as administrators, educators or leaders.

In some ways, the students recognize the professional components of nursing. Contributing to professional 
journals is somewhat important to the students even though they recognize that the average nurse rarely does so. This is clearly an indication that the students identify with a professional facet of nursing. Even so, they do not seem to be very interested in administration or management, both considered professional components.

The students were presented with seven questions asking how important a number of factors are to being a good nurse. Of these seven factors, intellectual curiosity was the least important. The students rejected the importance of intellectual curiosity, a personality trait associated with the role of a professional. Professions are defined in part by their exclusive possession of a body of knowledge (Collins 1990, pp. 18-19). As technology improves, so does knowledge, especially in medicine. Therefore, if nursing is a profession, one would expect intellectual curiosity to be important to acquire new information and advance the discipline. The students do not place importance on intellectual curiosity as a personality trait for nurses and thus do not perceive nursing in a way wholly consistent with the traditional definition of a profession.

Nonetheless, the students most likely see themselves as professionals, and nursing as a profession. But if a strict definition of the word "professional" is used, the students do not seem to be aspiring to the role of a full- 
fledged professional. This study cannot and is not meant to answer the question of whether or not nursing is a traditional profession, but as defined by these students nursing may lack some of the components of a profession. SUMMARY OF EXPECTATIONS, IDEALS, AND REALITY

\section{Summary of Expectations and Reality}

within the bounds of the limited information gained by this survey it appears that the students' expectations of the role of a nurse are reasonably consistent with the reality of nursing. The fact that the average age of the students was thirty-two and that most have had prior experience in health care makes it reasonable that they would have a good understanding of nursing.

The only significant disagreement involved administrative work and housekeeping tasks. It seems that, in general, the students underestimated the significance of administrative duties in nursing. This is likely not a very exciting component of nursing for most students. It is not surprising, therefore, that the students would not emphasize it. Additionally, the students seem to have overestimated the significance to nursing of housekeeping tasks. This is not unexpected in that many have had experience as aides or technicians, during which they would likely have done a larger proportion of these tasks than registered nurses and thus attribute more significance to 
them.

Although these students will likely experience some difficulty in assuming the role of a nurse after completing training, in general they seemed to have a good understanding of nursing and will not be surprised by what will be demanded of them. To the extent one can compare their understanding with that of Davis', Olesen's, and Whittaker's 1960's students, it appears that the contemporary students' understanding is better.

\section{Summary of Expectations and Ideals}

The students' expectations generally agreed with the reality of nursing as well as their nursing ideals. Their expectations appear to be consistent with their ideals concerning talking to and comforting patients, performing medical procedures, administrative work, and nursing diagnoses.

In other areas, however, disagreements are apparent between expectations and ideals. Working on patient charts is not overly important to the students, however, they are aware of the prevalence of charting in nursing. Additionally, meetings are not very important to the students, but they believe nurses attend meetings fairly often. Re-stocking supplies, cleaning, and making beds are not very important to the students, as expected, but they believe nurses do a lot of these tasks. Finally, the students indicate that contributing to professional 
journals is important to them, but they do not believe the average nurse is significantly involved in journal writing. The aforementioned disagreements are, in general, not surprising. It is expected that student nurses would not be excited about nor deem important the non-direct care aspects of nursing such as charting, meetings, re-stocking, cleaning or making beds. Also, as aspiring nurses it is expected that they would place importance on journal writing, a professional aspect of nursing.

The student nurses queried in this study were likely to be in their thirties and to have previously had fulltime occupations. They are predominately female, but males are present. The students are motivated to become nurses first and foremost by a desire to help others. They place considerable importance on the direct care component of nursing and very little importance on the non-direct care component. The students have a reasonably accurate grasp of the activities performed by the average nurse and are probably satisfied with their nursing experiences. If they could alter the structure of nursing, they would likely increase the direct care component.

\section{SUGGESTIONS FOR FUTURE RESEARCH}

This study represents only a cursory investigation of motivations, role conceptions, and demographics of student nurses. The study only briefly touched on an exploration 
of the agreement or lack thereof between students' expectations of the role of a nurse and the actual role of a nurse. Additionally, the same question could be posed to pre-nursing students as well as to graduating students.

Further study of the motivations of aspiring nurses would also be of interest. Currently, there is a surplus of nurses in many areas and a shortage in others. Many nurses with associate degrees feel they will have difficulty keeping their positions, and often go back to obtain a baccalaureate degree or a master's degree (Hurley 1994, pp. 34-35). These nurses could be queried in depth as to why they are going back and if they are satisfied with the role of nurse. Also, with some nurses having a hard time finding good positions, it could be helpful to discover if aspiring nurses are aware of the job outlook for nurses and if they are aware that their job possibilities would be enhanced if they continued for a baccalaureate or master's degree.

\section{CONCLUSIONS}

Nursing may or may not be a full-fledged profession, but it appears that the students surveyed for this study think of themselves as nascent professionals, though perhaps not in the traditional sense. They intend to make life-long careers of nursing even though they are generally starting their nursing education at a relatively late age. 
Like their predecessors they see nursing primarily as a caring and helping occupation. In general, they have a good understanding of the day-to-day work involved in being a nurse.

Changes in nursing education and nursing students will impact both the lives of nurses and health care. Nurses will likely expect more from their jobs. Many will want to achieve professional goals as well as maintain the more traditional caring and helping components of nursing. Because nurses are an integral part of the health care system, the changing outlooks of new nurses will probably lead to changes in the nursing role. For example, nurses may take on more of a partnership role with physicians while nurse's assistants and medical assistants acquire some of the traditional functions of nurses. Nursing, like other health care fields, is dynamic and invites additional inquiry. 


\section{REFERENCES}

Auster, Donald and N.R. Auster. 1970. Men Who Enter Nursing: Sociological Analysis. Canton, NY: By the authors, st. Lawrence University.

Becker, Howard S. 1960. "Notes on the Concept of Commitment." The American Journal of Sociology 66, No. 1 (July):3240 .

Benne, Kenneth D. and Warren Bennis. 1959. "Role Confusion and Conflict in Nursing: The Role of The Professional Nurse." The American Journal of Nursing (Feb):196-198.

Blustein, David L. 1988. "The Relationship between Motivational Processes and Career Exploration." Journal of Vocational Behavior 32:345-357.

Brown, JoAnne. 1992. The Definition of a Profession. Princeton, New Jersey: Princeton University Press.

Cockerham, William C. 1992. Medical Sociology. Englewood Cliffs, New Jersey: Prentice-Hall.

Collins, Randall. 1990. "Changing Conceptions in the Sociology of the Professions." In The Formation of Professions, ed. Rolf Torstendahl and Michael Burrage, 11-23, London: Sage Publications, 1990.

Corwin, Ronald G. 1960. "The Professional Employee: A study of Conflict in Nursing Roles." The American Journal of Sociology LXVI, No. 6:604-615.

Davis, Fred, ed. 1966. The Nursing Profession: Five Sociological Essays. New York: John Wiley \& Sons, Inc. - 1972. Illness, Interaction, and the self. Belmont, Ca: Wadsworth Publishing Company, Inc.

Davis, Fred, Virginia Olesen, and Elvi Whittaker. 1966. "Problems and Issues in Collegiate Nursing Education." In The Nursing Profession: Five Sociological Essays, ed. Fred Davis, 138-175, New York: John Wiley \& Sons, Inc.

Deci, Edward L. 1975. Intrinsic Motivation. New York: Plenum Press. 
and Richard M. Ryan. 1985. Intrinsic Motivation and Self-Determination in Human Behavior. New York: Plenum Press.

Elzinga, Aant. 1990. "The Knowledge Aspect of Professionalization: The Case of Science-based Nursing Education in Sweden." In The Formation of Professions, ed. Rolf Torstendahl and Michael Burrage, 151-185, London: Sage Publications.

Etzioni, Amitai, ed. 1969. The Semi-Professions and Their organization. New York: The Free Press.

Feyerherm, A.M. 1966. "Nursing Activity Patterns: A Guide to staffing." Nursing Research 15:122-134.

Fox, Renee C. 1989. The Sociology of Medicine: A Participant observer's View. Englewood Cliffs, NJ: Prentice-Hall.

Freidson, Eliot. 1970. Professional Dominance: The Social structure of Medical Care. New York: Atherton Press, Inc.

Gothler, Ann M. and Peri Rosenfeld. 1986. "Nursing Education Update: Enrollments and Admissions Trends." Nursing \& Health Care 7 (Dec.):555-559.

Greenwood, J. 1993. "The Apparent Desensitization of Student Nurses During their Professional Socialization: A Cognitive Perspective." Journal of Advanced Nursing 18:1471-1479.

Gross, Neal, Ward S. Mason, and Alexander W. McEachern. 1964 . Explorations in Role Analysis, Studies of the school Super-intendency Role. New York: John Wiley \& Sons, Inc.

Grossman, Divina Gracia S. and Celeste Northrop. 1993. "What High school students Think of a Nursing Career: A Survey of Dade County Senior High Schools." Journal of Nursing Education 32, No. 4 (April):157-162.

[Hess, Arthur E.]. 1983. Nursing and Nursing Education: Public Policies and Private Actions. Washington D.C.: National Academy Press.

Holtzclaw, Barbara J. 1983. "Crisis: Changing student Applicant Pools." Nursing \& Health Care 4 (Oct.):450454 .

Hurley, Mary Lou. 1994. "Where Will You Work Tomorrow?" NN (Aug.) : 31-35. 
Ickes, William and Eric S. Knowles, eds. 1982 . Personality, Roles, and Social Behavior. New York: Springer-Verlag.

Kapsar, Patricia P. 1982. "The Impact of Credentialing on Nursing." Medical Instrumentation 16, No. 5 (Sept.oct.) : 237-238 .

Katz, Fred. 1969. "Nurses." In The Semi-Professions and Their organization, ed. Amatai Etzioni, 54-81, New York: The Free Press.

Kersten, Joanne, Karen Bakewell, and Delois Meyer. 1991. "Motivating Factors in a student's Choice of Nursing as a Career." Journal of Nursing Education 30 , No. 1 (Jan.) : $30-33$.

Kiesler, Charles A. 1971. The Psychology of Commitment. New York: Academic Press, Inc.

Kiger, Alice M. 1993. "Accord and Discord in Students' Images of Nursing." Journal of Nursing Education 32:309-317.

Lake, W.H. 1987. Nursing staffing Based on Patient Classification. Rockville, MD: Information Management Services, Inc.

Linton, Ralph. 1936. Study of Man. New York: D. AppletonCentury Co., 114. Quoted in Neal Gross, Ward S. Mason, and Alexander W. McEachern, 1964. Explorations in Role Analysis. New York: John Wiley \& Sons, Inc.

Maslow, Abraham H. 1970. Motivation and Personality. New York: Harper \& Row, Publishers, Inc.

Mendez, Nana and Margaret Louis. 1991. "College Students' Image of Nursing as a Career Choice." Journal of Nursing Education 30 , No. 7 (Sept.):311-325.

Mills, C. Wright. 1959. The Sociological Imagination. New York: Oxford University Press.

Minyard, Karen, Jane Wall, and Richard Turner. 1986. "RNs May Cost Less Than You Think." Journal of Nursing Administration 16, No. 5 (May):28-34.

Misener, Terry R., A.J. Frelin, and Patricia A. Twist. 1987. "Sampling Nursing Time Pinpoints Staffing Needs." Nursing and Health Care 4 (April):233-237.

Mook, Douglas G. 1987. Motivation, The organization of Action. New York: W.W. Norton \& Co. 
Moses, Evelyn and Aleda Roth. 1979. "Nursepower: What Do Statistics Reveal About the Nation's Nurses?" American Journal of Nursing 79 (oct.):1745-1756.

National League for Nursing. 1992a. Nursing Data Review, 1992. New York: Division of Research: National League for Nursing Press.

- 1993b. Nursing Data Review, 1993. New York:

Division of Research: National League for Nursing Press.

- 1992a. Nursing Datasource 1992: Trends in Contemporary Nursing Education, Vol 1. New York: NLN Division of Research: National League for Nursing.

- 1993b. Nursing Datasource 1993: Trends in

Contemporary Nursing Education, Vol 1. New York: NLN Division of Research: National League for Nursing.

Olesen, Virginia L. and Elvi W. Whittaker. 1968. The Silent Dialoque: A study in the social Psychology of Professional Socialization. San Francisco: Jossey-Bass Inc.

Parisi, Lenard, Trudy Johnson, and Patricia Keill. 1993. "The Nursing Quality Professional: A Role in Transition." Journal of Nursing Care Quality 7 , No. 4 (July):1-5.

Patient Intensity for Nursing Index. 1988. In "Changing How Nurses Spend Their Time." 1991. Image: Journal of Nursing Scholarship 23, No. 1 (Spring):23-28.

Petri, Herbert L. 1986. Motivation: Theory and Research. 2d ed., Belmont, Ca: Wadsworth Publishing Company.

Rantz, Marilyn and Joan Duffy Hauer. 1987. "Analyzing Acute Care Nursing Staff Productivity." Nursing Management 18 , No. 4 (April) : 33-44.

Saren, M. and Straub, A. 1970. "Nursing Service Effectiveness." Hospitals 44:45-50.

Statistical Package for the Social Sciences, Release 1.10 1984, (SPSS/PC), Microsoft Corporation.

Stevens, Karen A. and Eleanor A. Walker. 1993. "Choosing a Career: Why Not Nursing for More High School Seniors?" Journal of Nursing Education. 32, No. 1 (Jan.):13-17.

Sullivan, Barbara. 1995. "Nursing Profession Hit by Wave of Changes as Hospitals Downsize to Cut Costs, Up Profits." Portland (OR.) The oregonian (Tues. March 7):B(15). 
Sullivan, Jean Langley and Donna M. Deane. 1994. "Caring: Reappropriating Our Tradition." Nursing Forum 29, No.2 (April-June) : 5-9.

United States Department of Labor. 1960. Part-Time Employment for Women. U.S. Government Printing office, Washington D.C.

United States Department of Health, Education and Welfare. 1973. Health Resources Statistics, Health Manpower \& Health Facilities, 1972-73 ed. Rockville, Md.

- 1977. Health Resources Statistics, Health Manpower \& Health Facilities, $1976-77$ ed. Hyattsville, Md.

Williams, Reg Arthur. 1973. "Characteristics of Male Baccalaureate students who selected Nursing as a Career." Nursing Research 22, No. 6 (Nov.-Dec.):520525 .

Williamson and Johnston. 1988. In "Changing How Nurses spend Their Time." 1991. Image: Journal of Nursing Scholarship 23, No. 1 (Spring):23-28.

Znaniecki, Florian. 1965. Social Relations and Social Roles. San Francisco: Chandler Publishing Company. 
APPENDIX A

QUESTIONNAIRE 
My name is steven Von Flue and I am conducting this experimental research as a requirement for the completion of a Master's degree in sociology at Portland State University.

This study is investigating the motivations, aspirations, experiences, and conceptions of nursing students. You may not receive any direct benefit from taking part in this study, but the information gained from this research will be used to gain a better understanding of individuals who enroll in nursing programs.

Your school has approved my asking you a number of questions included in the attached questionnaire. The questionnaire should take approximately ten to twelve minutes to complete.

The only foreseeable risk to you in completing this questionnaire is the inconvenience caused by the use of approximately twelve minutes of your time.

This survey is anonymous, please do not put your name anywhere on the questionnaire. One of your fellow students or your instructor will collect the questionnaires so that I cannot associate a completed form with an individual.

You do not have to take part in this survey and your refusal to do so or your withdrawal from it at any point will in no way affect your course grade or your relationship with your school. Your participation, however, is valued and crucial to this research.

Feel free to ask any questions that you may have. you may contact me later through the Sociology Department at Portland State University, (503)725-3926. If you desire you may remove and retain this page of the questionnaire.

If you have concerns or questions about this study, please contact the Chair of the Human Subjects Research Review Committee and Sponsored Projects, 105 Neuberger Hall, Portland State University: (503)725-3417. 
1) Please check all of the following that apply by indicating how you would complete the following sentence. "I chose nursing because ...."

-I want to help people

-I want to do important work $\ldots \ldots \ldots \ldots \ldots \ldots$

-I want to be respected.

-the salary's good..

-of the hours

-nurses can always get a job

-nursing is exciting

-nurses work with a variety of people

-I want to meet a companion/future spouse

2) Indicate the importance of the following groups of people in influencing your decision to study nursing.

$$
\text { very moderately what } \frac{\text { some- }}{\text { not at all }}
$$

-family

-friends

-teachers

-co-workers

-guidance counselors
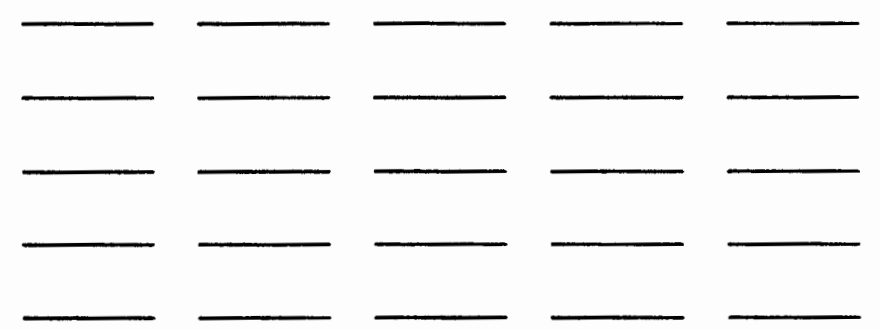
3) Again, indicate the importance of the following items in influencing your decision to study nursing.

$$
\text { very moderately what not at all }
$$
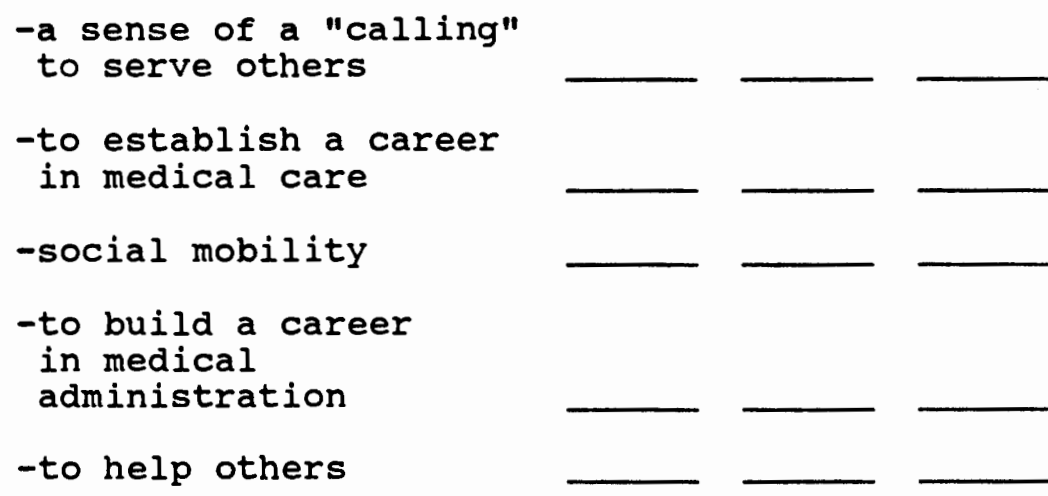

4) Which of the following were a factor in your decision to study nursing?

(check all that apply)

-I knew a nurse personally

-someone in my family is a nurse

-I took care of a seriously ill person

-I lived with a seriously ill person

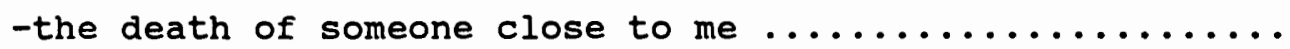


5) For each of the following activities indicate how important they are as a contribution to a nurse's duties. (This refers to the significance of the activities in terms of their importance to the role of a nurse)

$$
\text { very moderately what } \frac{\text { some- }}{\text { not }} \text { not all }
$$
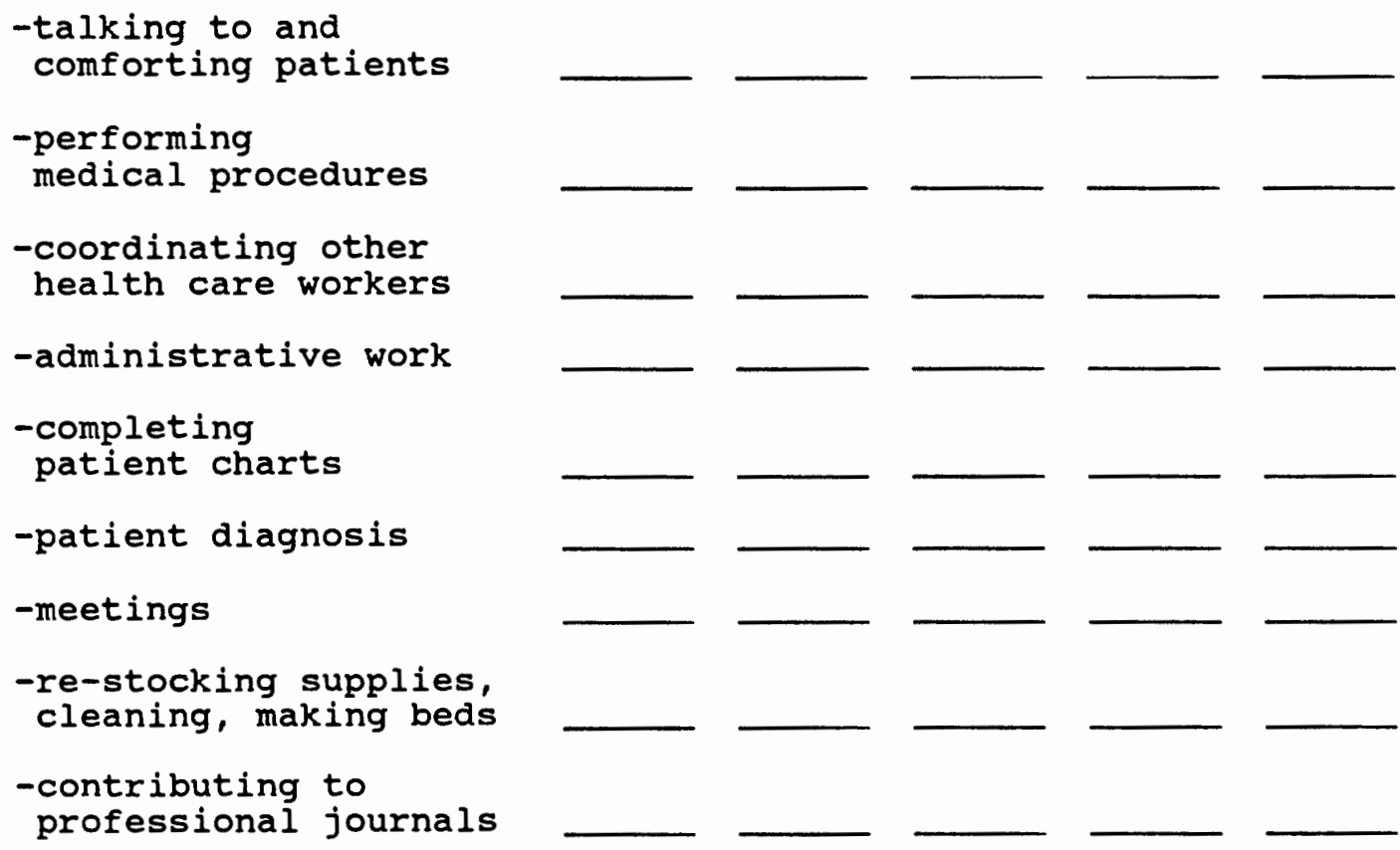

6) Rank the following in terms of their importance as characteristics of a good nurse.

very moderately what $\frac{\text { some- }}{\text { not at all }}$

-intellectual curiosity

-good decision making and problem solving ability

-ability to efficiently follow directions

-good communication skills

-ability to tolerate stress 
7) Indicate how often the average practicing nurse engages in the following activities.

always often sometimes seldom never

-talking to and
comforting patients
-performing
medical procedures
-coordinating
patient care
-administrative
work
-coordinating other
health care workers
-completing
patient charts
-patient
diagnosis
-meetings
-re-stocking supplies,
cleaning, making beds
-contributing to
professional journals
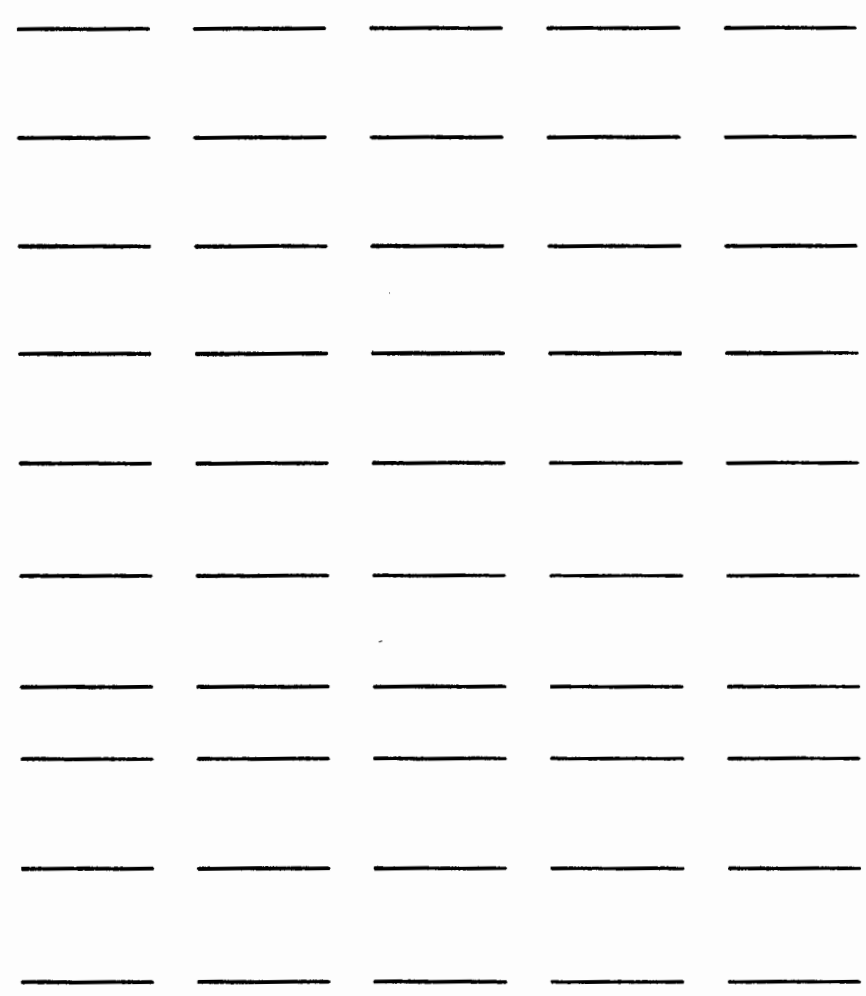

8) Most nurses have particular functions depending upon where they are employed. Following are some of the most frequent functions of nurses. Indicate your opinion of what percentage of all employed nurses spend most of their time in each of the activities below. (10\%, 25\%, 50\%, etc.)

-direct patient care activities ...........

-supervisory duties

-teaching

-administrative activities

-other (specify)

-no one dominant function 
9) For nurses who spend most of their time in direct patient care, which of the following do you believe to be part of their routine activities?

(Simply check the items you believe to be routine)

-Performing physical examinations

-developing and modifying medication requirements .......

-implementing therapy

-administering medications

-assisting the physician during patient examination

-developing therapeutic plans

-instructing patients and families in health promotion

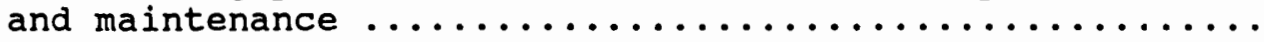

-instructing patients in management of diagnosed

illness

-obtaining health histories

-sustaining and supporting persons who are impaired or ill during programs of diagnosis or therapy ........... -other (specify)

10) At what age did you first become interested in nursing?

11) Do you intend to work full-time as a nurse until you

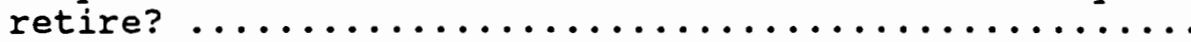

12) Have you worked in the health care field prior to enrolling in nursing school? .... yes no

13) Please list the jobs or occupations you have had, starting with the most recent one ............... 
14) What is your age?

15) You are ... male female divorced widowed

16) You are ....... single married

17) You have children .. yes no

18) Indicate the most advanced degree that you have obtained.

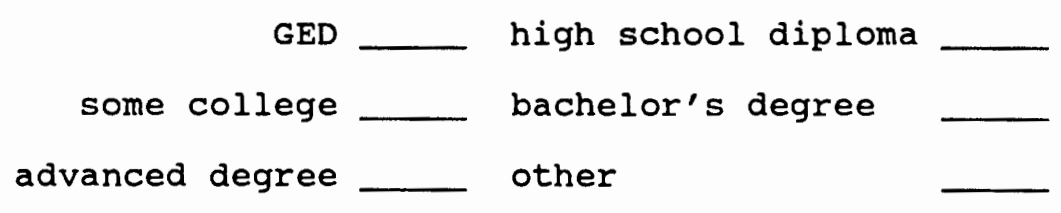

19) If you do not yet have a bachelor's degree, are you working on or intend to receive one in the future? ................... no yes

20) In what area of nursing do you intend to work.
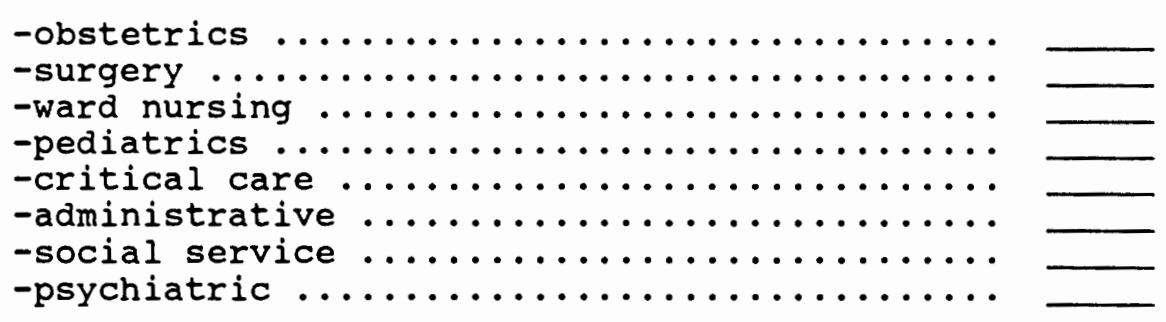

21) In which of the following settings do you intend to work.
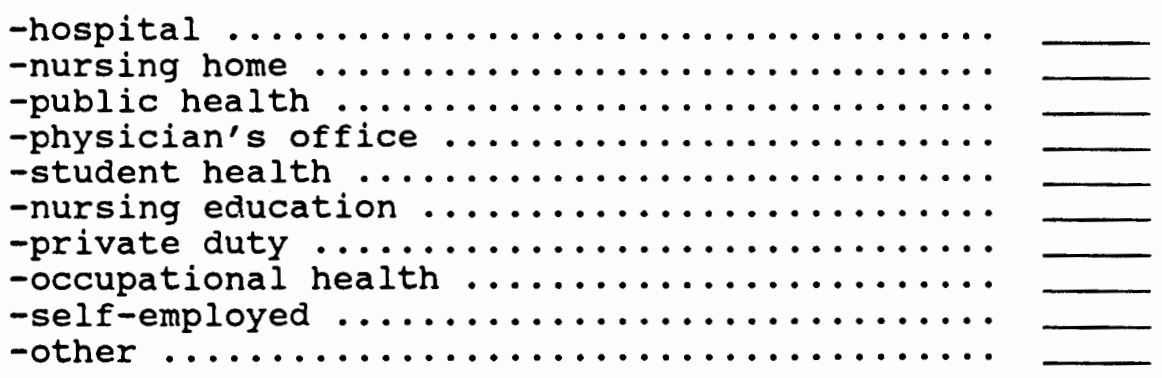


\section{APPENDIX B}

RESEARCH APPROVAL REQUEST SUBMITTED TO THE HUMAN SUBJECTS RESEARCH REVIEW COMMITTEE AND APPROVAL 


\section{PROJECT TITLE AND PROSPECTUS}

The Motivations, Aspirations, Experiences, and Conceptions of Student Nurses. This project will involve surveying first year nursing students at two different schools. Access to classes will be requested in order to complete the surveys. The intent is to ascertain what factors motivated the students to pursue nursing and nursing education. Additionally, I will ask about the students' backgrounds including a number of demographic questions in order to discover what kinds of individuals are entering nursing programs. Finally, students will be queried about their understanding of the role of a nurse. This includes asking what activities they believe are important to the role of a nurse as well as what activities they believe nurses are routinely performing. The purpose of these last questions is to gain an understanding of the agreement or lack thereof between nursing students' conceptions of nursing and the realities of nursing. Nursing is a dynamic occupation which has undergone considerable professionalization, diversification, and has seen salaries increase during the last three decades. The goal of this research is to explore whether there has been a corresponding change in nursing students. The findings of this research will be compared with similar research from the last three decades.

The proposed research will not be conducted pursuant to a contract or grant.

\section{EXEMPTION CLAIMS:}

This research falls into exemption category (3) on page four of the Application for Review of the Protection of Human subjects in Proposed Research. The research involves the use of survey procedures. Because there will be anonymity (no names will be on the surveys) and the surveys will be collected by a student or instructor in such a way that the investigator will be unable to associate a particular completed survey with a student, the subjects will not be identified either directly or indirectly. Additionally, any disclosure of the human subjects' responses will not reasonably place them at risk as the nature of the questions asked are rather innocuous.

III. SUBJECT RECRUITMENT:

Two different types of nursing schools will be selected. Both an Associate degree program and a Bachelor's degree program will be selected in order to provide contrast between the different types of individuals that they may attract. The schools will be in the Portland area, and will be chosen to be as dissimilar as possible with the limitation of receiving permission to survey students. All first-year students in the chosen programs will be part of the survey pool. All students who agree to be surveyed will be included. 
IV. INFORMED VOLUNTARY CONSENT IN WRITING:

All subjects will be adults. Any students less than 18 years of age will be excluded from the study. An informed consent form will serve as a cover page for the survey. subjects will not be asked to sign the form as this would violate the anonymity of the project.

V. FIRST-PERSON SCENARIO:

"I was seated at my desk in class when the investigator walked in. After the investigator had a brief conversation with my instructor, he asked for everyone's attention and then gave a brief explanation that he was a Master's degree candidate conducting research involving nursing students. He asked for my cooperation and proceeded to pass out surveys to the class. He then read the cover page of the survey and asked if we had any questions. I volunteered to complete the survey and did so which took about twelve minutes. When I was done the instructor collected the surveys and handed them in one stack to the investigator. The investigator thanked us and left."

vI. POTENTIAL RISRS AND SAFEGUARDS:

The only foreseeable risk would be a risk of inconvenience as the survey will take approximately ten to twelve minutes to complete. The research will be approved by the school as well as the instructor, therefore the time will be allotted so as not to conflict with course material. Also, an attempt will be made to start the survey several minutes prior to official class time in an effort to minimize inconvenience.

VII. POTENTIAL BENEFITS OF THE PROPOSED STUDY:

The anticipated benefits are improved understanding of motivations, intentions, and conceptions of nursing students. This may lead to improved recruiting techniques for nursing schools as well as provide insight for those considering a career in nursing. In light of a shortage of nurses in many areas, recruiting qualified students is an important component of nursing education.

VIII.RECORDS AND DISTRIBUTION:

In no way will subjects be identified with their responses as the surveys will be anonymous. If the results are published, they will be in statistical form with no reference to individuals. 


\title{
OFFICE OF GRADUATE STUDIES AND RESEARCH
}

Research and Sponsored Projects

DATE: $\quad$ May 4th 1995

TO: $\quad$ Steven Von Flue $\quad$ Social Security \#: 541-96-9329

FROM: for Laurie Skokan, Chair, HSRRC, 1994-95 Muen hovinges

RE: Your HSRRC Application entitled "The Motivation, Aspirations, Experiences, and Conceptions of Student Nurses"

In accordance with your request, the Human Subjects Research Review Committee has reviewed your application for compliance with Department of Health and Human Services policies and regulations on the protection of human subjects.

The committee will be satisfied that your provisions for protecting the rights and welfare of all subjects participating in the research are adequate if you prepare a written response to the following items(s):

1. On the bottom of your cover letter please correct the name of our office. It should say "...Review Committee, Office of Research and Sponsored Projects."

2. Even though this is not a requirement for HSRRC approval, Committee suggests that you re-word $\# 5$ in question $\# 1$ of your survey. It is vague as stated.

Upon receipt of the above revisions and your response to this memo in the Office of Graduate Studies and Research, I will resume the processing of your application.

\author{
c: Maureen Orr Eldred \\ Joseph F. Jones, Project Advisor
}

conditnl.men 